\title{
Rol de la imagenología en el proceso diagnóstico de la patología ginecológica benigna
}

\author{
Álvaro Huete G. ${ }^{1}$, José Craig V. ${ }^{2}$, M. Catalina Vial A. ${ }^{1}$, Marcelo Farías J. ${ }^{2}$, Harumi \\ Tsunekawa ${ }^{2}$, Mauricio Cuello $F^{2}$ \\ ${ }^{1}$ Departamento de Radiología, Facultad de Medicina, Pontificia Universidad Católica de Chile. ${ }^{2}$ División de Obstetricia y \\ Ginecología, Facultad de Medicina, Pontificia Universidad Católica de Chile.
}

Los autores Álvaro Huete y José Craig contribuyeron igualmente a la preparación del manuscrito.

\section{RESUMEN}

En la actualidad, la selección y uso correcto de los diferentes métodos de imágenes disponibles (ecografía, tomografía axial computada y resonancia magnética) constituye uno de los pilares fundamentales para el adecuado proceso diagnóstico en ginecología. Para la mayoría de las patologías benignas que comprometen al aparato genital femenino, la ecografía transvaginal es una herramienta sensible, de fácil acceso, costo-efectiva y por tanto debiese constituir el método inicial de elección. Sin embargo, su eficacia depende de que el operador sea entrenado y experimentado en su interpretación. El uso de la tomografía computada (TC) y la resonancia magnética (RM) debiese restringirse a condiciones específicas, en especial para caracterizar lesiones que no son completamente evaluables por ultrasonido. La mayor utilidad de la TC está en el diagnóstico diferencial de las urgencias ginecológicas, en evaluar el compromiso extra pelviano de neoplasias anexiales y en el estudio preoperatorio de anomalías de la vía urinaria. Respecto de la RM, su mayor utilidad está en el estudio de lesiones anexiales complejas a la ultrasonografía, endometriosis pélvica profunda y extra pelviana, adenomiosis, malformaciones uterinas, etapificación local de neoplasias endometriales, cervicales y vaginales, y en la evaluación de miomas múltiples o extra pelvianos.

\section{PALABRAS CLAVE: Ecografía, tomografía computada, resonancia magnética, tumor anexial, sangrado uterino anormal, dolor pélvico}

\section{SUMMARY}

In gynecology, the selection and proper use of the different available imaging methods (ultrasound, computed tomography and magnetic resonance) is paramount for a proper diagnostic process. For most benign conditions affecting the female genital tract, transvaginal ultrasound constitutes an exam with has excellent sensitive, is readily accessible and cost-effective, therefore being the initial method of choice. However, its effectiveness depends on the operator training and expertise in interpretation. The use of computed tomography (CT) and magnetic resonance imaging (MRI) ought to be restricted for specific conditions, especially to characterize lesions not completely evaluated by ultrasound. The main benefit of $\mathrm{CT}$ is in the differential diagnosis of gynecological emergencies, in assessing extra pelvic extension of adnexal masses and in the preoperative assessment of urinary tract abnormalities. Regarding MRI it is most useful in the study of complex adnexal lesions, extra pelvic and deep pelvic endometriosis, adenomyosis, uterine malformations, local staging of endometrial, cervical and vaginal neoplasms, and multiple or extra pelvic leiomyomas.

KEY WORDS: Ultrasound, computed tomography, magnetic resonance imaging, adnexal mass, abnormal uterine bleeding, pelvic pain 


\section{INTRODUCCIÓN}

Ante la sospecha de una patología ginecológica, para acotar el diagnóstico diferencial, el ginecólogo debe apoyarse en un método de diagnóstico por imágenes. Los motivos de consulta más frecuentes en ginecología son: dolor pelviano, alteraciones del ritmo menstrual o flujo genital anormal. Estos son, por lo general, manifestación de un compromiso del sistema reproductor femenino. En el correcto planteamiento de un diagnóstico diferencial se debe considerar, en primer lugar, la edad y la actividad sexual de la paciente. Esta información, sumada a la prevalencia de las distintas etiologías, permite esgrimir una adecuada sospecha diagnóstica. Así, por ejemplo, la probabilidad de que una mujer premenárquica o postmenopáusica que consulta por dolor pélvico y atraso menstrual tenga un embarazo ectópico es cercana a cero, dado la baja prevalencia que tal condición tiene en dichos grupos etarios, probabilidad que debiese excluirse del diagnostico diferencial si no ha habido actividad sexual.

Elementos adicionales que nos orientan y permiten afinar nuestra sospecha diagnóstica se obtienen de una buena anamnesis y un adecuado examen físico general y ginecológico, para así apoyar con mayor o menor grado de certeza un posible diagnóstico $(1,2)$.

Tomando en conjunto la prevalencia de la patología junto con los factores de riesgo de la paciente, sumado a los signos, síntomas y hallazgos positivos al examen clínico, es posible definir la probabilidad clínica de que dicha patología este presente, siendo esta la probabilidad pre-test. Si esta probabilidad es lo suficientemente baja, se puede descartar con alta confianza una etiología específica. Una vez descartada esa hipótesis diagnóstica, es necesario plantear nuevas etiologías que expliquen el cuadro clínico antes de iniciar cualquier tratamiento. Por otro lado, si la probabilidad pre-test es alta y permite sustentar la causa del cuadro clínico, se puede dar paso a un tratamiento adecuado.

En las ocasiones donde la probabilidad pretest es intermedia, sobretodo ante la posibilidad de etiologías diversas con manejo variable, será necesario considerar el uso de exámenes complementarios que permitan acotar dicha probabilidad y definir una terapia específica (3). En este contexto, los exámenes de imágenes apoyan al proceso diagnóstico ginecológico y optimizan el valor de la probabilidad de dicha patología, esto es la probabilidad post-test. Idealmente, con una adecuada selección de estudios imagenológicos, etiologías específicas podrán confirmarse o descartarse con certeza.

Al seleccionar una técnica imagenológica, el especialista debe considerar no sólo las ventajas diagnósticas que el método ofrece sino también su disponibilidad, los riesgos de la técnica, sus costos asociados y su rendimiento (sensibilidad y especificidad) de acuerdo a las hipótesis diagnósticas que se manejen.

La técnica más utilizada en ginecología es la ecografía transvaginal (EcoTV). Esta es una técnica segura, de fácil acceso, bajo costo, y que, en los equipos más nuevos, tiene excelente resolución espacial y temporal. Su uso ha facilitado el diagnóstico diferencial de la patología anexial y endometrial, en muchas ocasiones sin requerir de otras imágenes, llegando a índices de certeza diagnóstica mayores al $90 \%$ en algunas condiciones (4-6). No obstante, existe gran dispersión en la capacidad diagnóstica de la EcoTV al evaluar determinadas patologías. En dicho escenario, surge la necesidad de complementar la EcoTV con otro método de imagen. De estos, la tomografía computada (TC) y la resonancia magnética $(\mathrm{RM})$ tienen un rol en el diagnóstico y pueden complementar o constituir una mejor alternativa a la EcoTV (7).

En este trabajo se revisan las indicaciones de los estudios de imágenes en el proceso diagnóstico en ginecología general. Incluido está un análisis del rol que tienen tres de las técnicas de imágenes actualmente disponibles: 1) EcoTV, con o sin Doppler-color; 2) TC y 3) RM. El análisis se centra en la utilidad clínica que cada una de estas técnicas tiene en el enfrentamiento de tres problemas frecuentes en ginecología: 1) la urgencia ginecológica asociada a algia pelviana aguda, 2) la patología uterina benigna y 3) el tumor anexial.

\section{Proceso diagnóstico en ginecología general}

Una vez que se ha restringido la hipótesis diagnóstica, basado en la evaluación clínica y se ha concluido que la probabilidad pre-test para dicho diagnóstico es intermedia, entonces se justifica el recurrir al uso de métodos de imágenes de apoyo para clarificar posibles etiologías (8). Al momento de seleccionar un método de imagen, es importante que el ginecólogo conozca y considere para su decisión cuatro puntos:

1) Certeza diagnóstica: Esto es, el conjunto de índices de capacidad diagnóstica que un examen tiene para una patología particular (sensibilidad, especificidad, valor predictivo positivo, valor predictivo negativo, cociente de probabilidades positivo [likelihood ratio, LR+] y negativo [LR-]) (3).

2) Disponibilidad del método: Se refiere a la existencia física del equipo y disponibilidad horaria para realizar el examen.

3) Costo: Considera el valor unitario de la prestación.

4) Resultado: Implica el lapso de tiempo para la disponibilidad de un informe especializado. 
No existiendo restricciones de los tres últimos aspectos, lo que debiese comandar la elección es la capacidad diagnóstica del método.

\section{Métodos diagnósticos en ginecología general}

Existen diversas técnicas de diagnóstico que se utilizan en ginecología. En ésta revisión analizaremos las más relevantes y cuyos resultados están validados por la práctica clínica y la evidencia disponible (Tabla I).

Para la mayoría de los casos asociados a los tres problemas clínicos antes planteados, la primera elección del ginecólogo ha sido históricamente la EcoTV. Ello basado en la mayor disponibilidad y distribución de este recurso, tanto en centros de baja como alta complejidad, el no requerir mayor preparación previa, una baja tasa de riesgos, menor costo comparativo y la familiaridad que el ginecólogo tiene con la ejecución e interpretación de las imágenes que esta metodología entrega.
Por lo general, en gineco-obstetricia se considera que las técnicas de imagen más sofisticadas, como TC y RM, están reservadas a los casos más complejos en que queden dudas tras la ecografía convencional, ya que son métodos de extraordinaria capacidad de resolución por contraste con buena resolución espacial (Figura 1). Sin embargo, sus índices diagnósticos son similares al US en muchas de las patologías benignas de dolor pelviano agudo (9). Por tanto, no siempre su uso conllevará a mejorar la información otorgada por la US (10). Esta situación convierte a estas técnicas en alternativas superiores sólo en casos muy particulares (11).

Por otro lado, al momento de solicitar estas imágenes complementarias, se deben considerar sus desventajas prácticas. En algunos lugares, tanto la $\mathrm{TC}$, pero especialmente la RM, tienen poca disponibilidad, mayor costo y resultados diferidos. Además, pueden requerir de alguna preparación previa y tienen riesgos asociados al método (ej. alergia a medio de contraste, nefropatía por contraste, radiación ionizante en mujeres en edad fértil).

Tabla I

TÉCNICAS DE DIAGNÓSTICO POR IMÁGENES DE USO HABITUAL EN GINECOLOGÍA

\begin{tabular}{|c|c|c|}
\hline \multicolumn{3}{|c|}{ NO IONIZANTE } \\
\hline & Ventajas & Desventajas \\
\hline \multirow[t]{5}{*}{ US } & Fácil acceso & Operador dependiente \\
\hline & Rápida & Campo visual restringido \\
\hline & Bajo costo & Menor resolución de contraste y espacial \\
\hline & Inocua & Mayores artefactos (aire, tejido adiposo, etc) \\
\hline & Prontitud del informe & \\
\hline \multirow[t]{8}{*}{$\mathrm{RM}$} & Excelente resolución de contraste & Disponibilidad limitada \\
\hline & Mayor campo visual & Mayor tiempo de adquisición \\
\hline & Campo visual amplio & Alto costo \\
\hline & Adquisiciones volumétricas en varios planos & Contraindicaciones (marcapasos, claustrofobia, prótesis) \\
\hline & Reproducible & Menor resolución temporal \\
\hline & Inocua* & $\begin{array}{l}\text { Reacción adversa al gadolinio en pacientes con insufi- } \\
\text { ciencia renal: fibrosis nefrogénica sistémica (NFS). } \\
\text { Gadolinio contraindicado en embarazo }\end{array}$ \\
\hline & & NTE \\
\hline & Ventajas & Desventajas \\
\hline \multirow[t]{5}{*}{ TC } & Excelente resolución espacial & Radiación ionizante \\
\hline & Buena resolución de contraste & Reacciones adversas al medio de contraste iodado \\
\hline & Reproducible & Costo intermedio \\
\hline & Rápida & Disponibilidad intermedia \\
\hline & Permite reconstrucción multiplanar & Uso muy limitado en embarazo \\
\hline
\end{tabular}

US: ultrasonido. RM: resonancia magnética. TC: tomografía computada. * La RM se considera inocua, ya que bien indicada no presenta mayores riesgos, sin embargo, el uso de gadolinio en pacientes con insuficiencia renal crónica, se asocia a efectos adversos (NFS). 


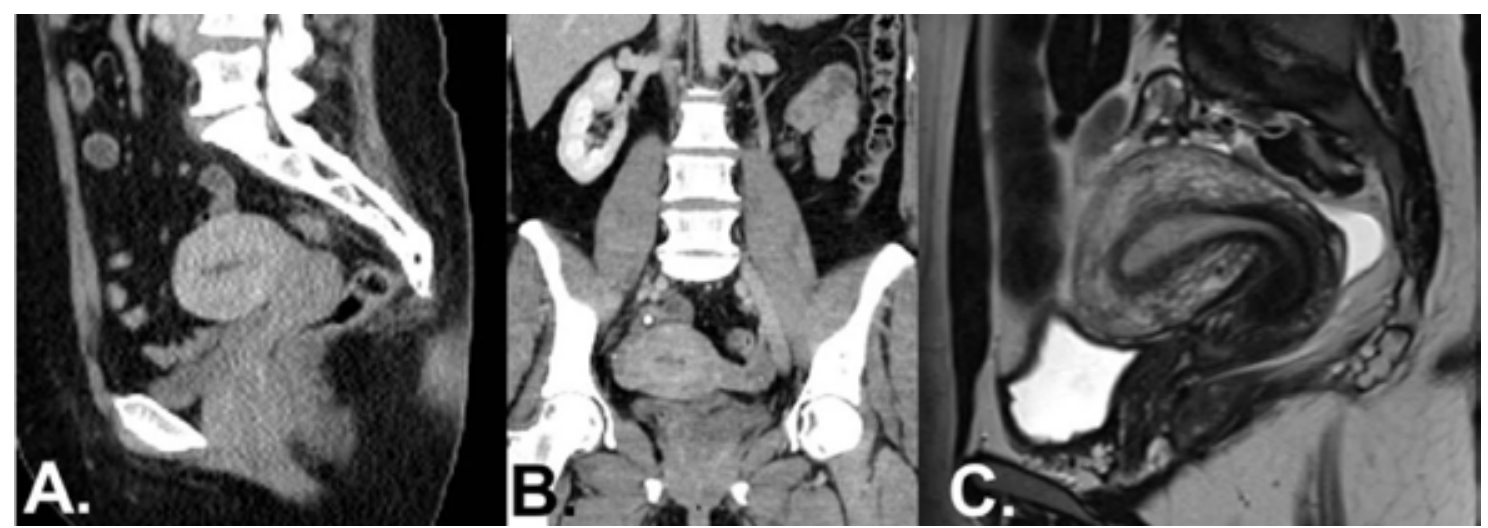

Figura 1. Imágenes complementarias en el estudio de pelvis femenina. Se presentan dos ejemplos de pelvis femenina adquiridos en cortes sagitales y coronales de tomografía computada (A, B) y corte sagital de resonancia magnética $(\mathrm{C})$.

\section{Rol de las imágenes en la patología ginecológica}

En la práctica ginecológica habitual las patologías más frecuentes pueden agruparse en 3 grandes áreas. Éstas son: I. Urgencias ginecológicas. II. Patología uterina benigna. III. Patología anexial benigna.

A continuación se comentará la aplicación y utilidad de las diversas técnicas de imagen en cada grupo de patologías, poniendo énfasis en el análisis comparativo entre ellas.

I. Urgencias ginecológicas. Se refiere al grupo de patologías de origen ginecológico o relacionadas con las etapas tempranas del embarazo (ej. embarazo ectópico), cuya presentación es aguda y cuyo síntoma predominante es el dolor pélvico (10-13). Las cinco patologías más frecuentes son: embarazo ectópico $(40 \%)$, proceso inflamatorio pelviano, rotura folicular sintomática, cuerpo lúteo hemorrágico y torsión anexial (11).

I.a. Embarazo ectópico. El embarazo ectópico (EE) es la primera causa de emergencia en ginecología. En nuestro país se registran aproximadamente 3.700 casos de embarazo ectópico al año, cifra que equivale al $1,4 \%$ de los nacidos vivos en dicho período (14). Su importancia, desde el punto de vista de la salud pública, radica en que el EE todavía constituye una de las causas relevantes de muerte materna durante el primer trimestre del embarazo tanto en Chile como en el resto del mundo (15). Frente a la sospecha clínica de EE, la ecoTV constituye la primera herramienta diagnóstica (16). El valor crítico de subunidad $B$ de gonadotrofina coriónica (B-hCG) para visualizar el saco gestacional por ecoTV debe ser mayor a $1000 \mathrm{mUl} / \mathrm{mL}$. Considerando la historia clínica, el uso de marcador gestacional y los hallazgos a la ultrasonografía, es posible definir las siguientes variedades clínicoultrasonográficas (17-19) (Figura 2):
1) Hallazgo ecográfico de una cavidad endometrial vacía (ausencia de saco gestacional intrauterino), en presencia de valores de subunidad B-hCG $>1.000 \mathrm{mU} / \mathrm{mL}$ y anexos normales. Esta forma de presentación representando el 20 a 25\% de los EE. 2) En el mismo escenario anterior pero en presencia de un tumor anexial complejo, es la forma de presentación más común (signo de blob) y representando el 40 a $57 \%$ de los casos de EE.

3) Otra forma de presentación en ausencia de gestación intrauterina es la detección al US de un anillo tubario o 'signo de bagel' (hallazgo característico de EE), con niveles de B-hCG > $1.000 \mathrm{mU} / \mathrm{mL}$, esta representa el 20 a $25 \%$ de los casos de EE.

4) La detección de un saco gestacional con saco vitelino o polo embrionario en la región anexial corresponde a un 10 a $13 \%$ de los casos de EE.

5) El hallazgo de un saco gestacional con embrión vivo en una de las regiones anexiales, representa alrededor del 5 a $7 \%$ de los casos de EE.

Aunque existen otras formas de presentación posibles, todas ellas son inespecíficas y no orientan el diagnóstico a EE (16). Los hallazgos tomográficos de un EE son inespecíficos. Sin embargo, en ocasiones la TC puede ser el primer examen solicitado en servicios de urgencia para pacientes que debutan con un abdomen agudo e hipotensión. La combinación de lesión quística hemorrágica anexial, rodeada de abundante vascularización mesogonadal y con hemoperitoneo asociado tiene un alto valor predictivo positivo para EE (Figura 3). Para un EE de localización extra ovárica, hasta el 1,4\% de los casos, el uso de TC es fundamental, para establecer su correcta ubicación y su potencial compromiso vascular. La RM, por su parte, contribuye para evaluar el grado de adherencia placentaria a los órganos, lo que facilita la planificación quirúrgica $(21,22)$. Los índices de capacidad diagnóstica para el US en relación a EE se presentan en la Tabla II. 


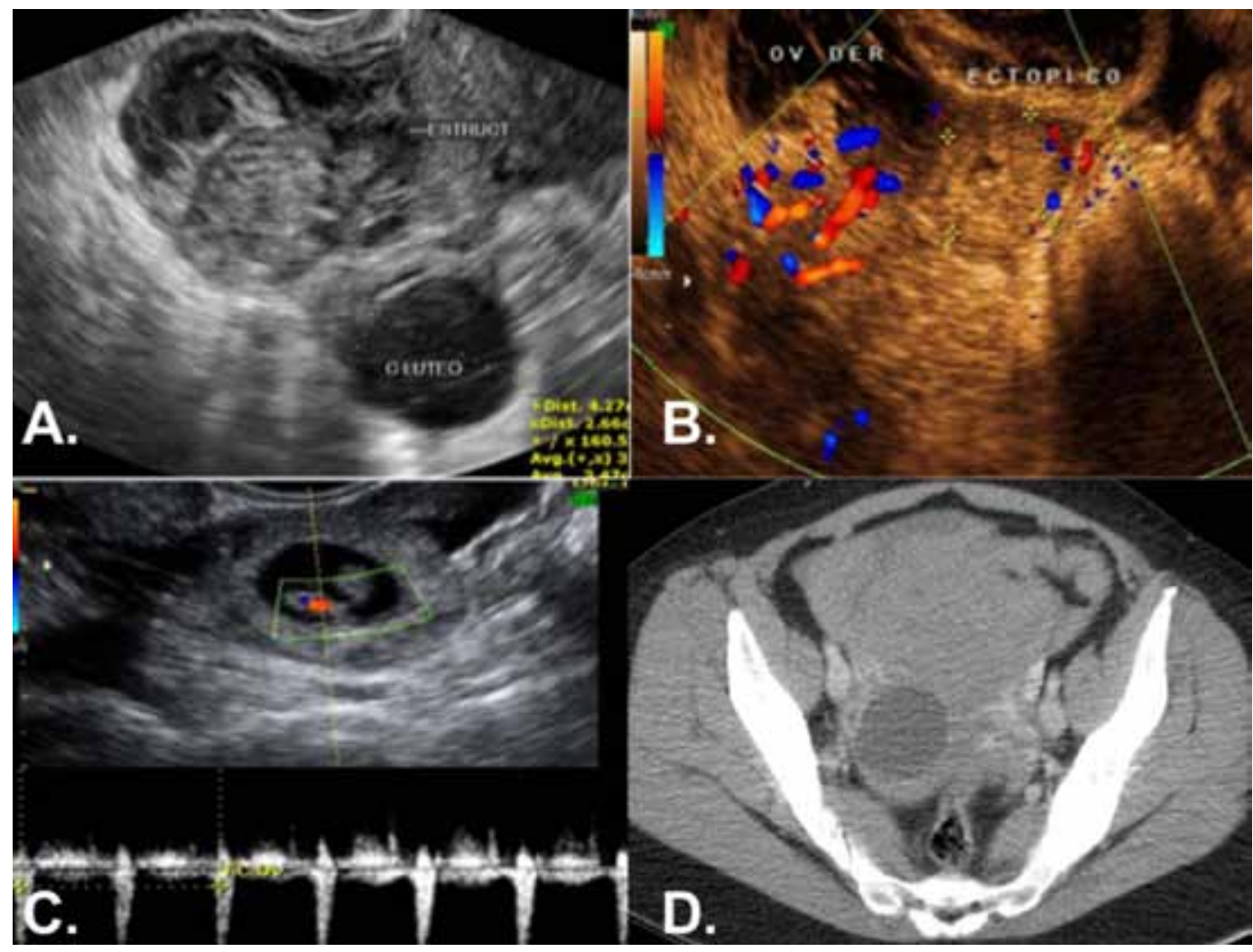

Figura 2. Imágenes en embarazo ectópico. Visualización de 3 formas clínicas de embarazo ectópico al ultrasonido: A) tumor anexial complejo; B) Anillo tubario; C) saco gestacional extrauterino localizado en región anexial, con embrión que presenta latidos cardiofetales (+) al análisis de flujometría Doppler. D) embarazo ectópico roto en $\mathrm{CT}$, observando un saco gestacional anexial derecho, asociado a un hemoperitoneo.

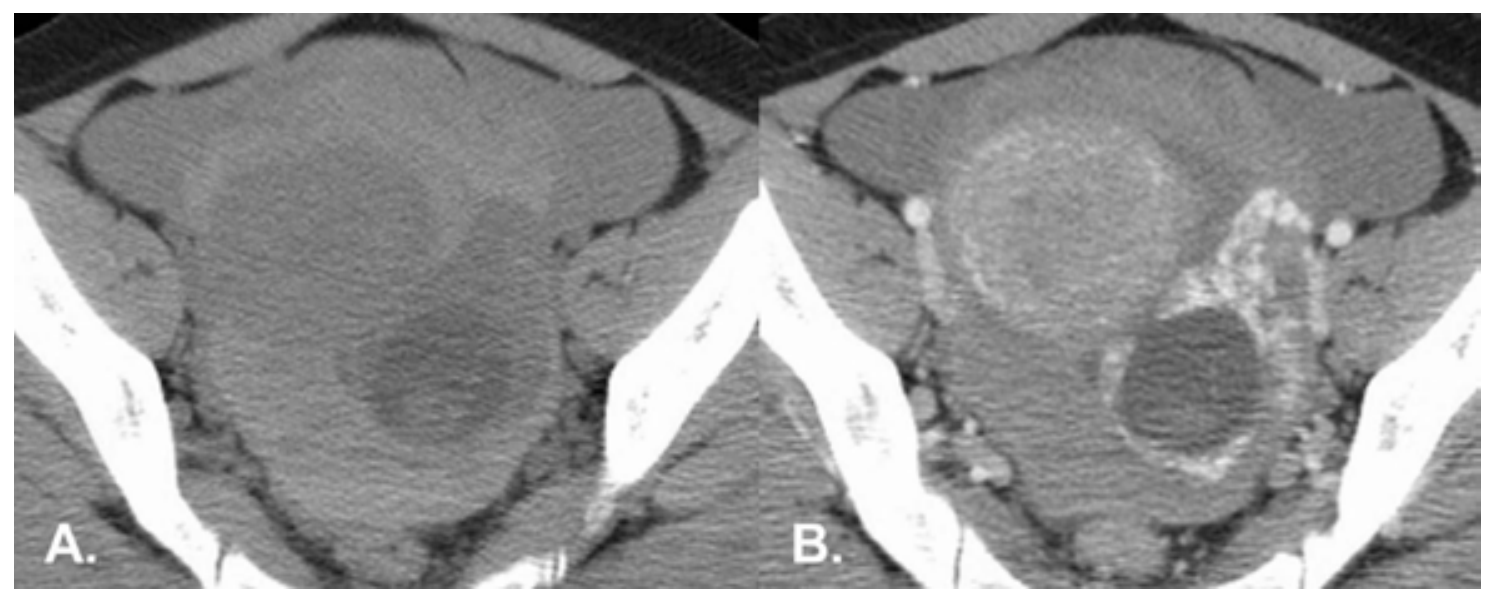

Figura 3. Embarazo ectópico anexial. En la TC sin contraste (A) se observa hemoperitoneo y una lesión anexial izquierda quística consistente con saco gestacional. Con el uso de medio de contraste endovenoso (B) se evidencia abundante vascularización mesogonadal izquierda. Estos hallazgos tienen un alto VPP para embarazo ectópico. 


\section{Tabla II \\ CAPACIDAD DIAGNÓSTICA DE LA ECOGRAFÍA TRANSVAGINAL Y LA MEDICIÓN DE B-hCG* CUANTITATIVA PARA EMBARAZO ECTÓPICO}

\begin{tabular}{lcc}
\hline Combinación diagnóstica & Sensibilidad (\%) & Especificidad (\%) \\
\hline Útero vacío con B-hCG (+) & 74 & 80 \\
Tumor anexial con B-hCG (+) & 80 & 85 \\
Anillo tubario con B-hCG (+) & 85 & 90 \\
Embrión ectópico con LCF (+) & 100 & 100
\end{tabular}

*B-hCG: Subunidad beta de gonadotrofina coriónica humana (Tabla tomada y modificada de ref. 16).

I.b. Proceso inflamatorio pelviano. El proceso inflamatorio pelviano (PIP) es la segunda causa más frecuente de urgencia ginecológica. Corresponde a un conjunto de cuadros infecciosos que afectan al tracto genital femenino, comprometiendo útero y anexos uterinos. Su gravedad clínica se relaciona al grado de compromiso de cada uno de ellos, el agente causal, la condición clínica basal de la paciente y el tiempo de evolución transcurrido al momento de su diagnóstico. Así puede haber cuadros de endometritis, endometritis-salpingitis, salpingitis aguda o crónica, piosalpinx, absceso tubo-ovárico (ATO), pelviperitonitis y peritonitis generalizada. Exceptuando el ATO y el piosalpinx, para la mayoría de las entidades agrupadas en esta condición, la ecografía tiene escasa eficacia diagnóstica $(20,23,24)$.

EI ATO corresponde a una lesión masiforme anexial heterogénea, mal delimitada, que incluye ovario y trompa y que contiene una o mas colecciones purulentas (25). Frente a la sospecha de ATO, los hallazgos ecográficos que apoyan dicho diagnóstico son la presencia de áreas quísticas heterogéneas y de ecogenicidad intermedia (compatible con material purulento) en la masa, la presencia de señal vascular periférica al estudio Doppler-color y, en especial, la inducción de dolor intenso al momento de contactar o desplazar el transductor en la región axial afectada (Figura 4A). A diferencia del ATO, el piosalpinx corresponde al compromiso infeccioso aislado de la trompa uterina, identificando una colección purulenta al interior del lumen tubario. Ecográficamente se observará una lesión tubular bien delimitada, con tabiques incompletos y contenido de ecogenicidad intermedia y heterogéneo, compatible con pus (Figura 4B).

Tal como lo señalamos previamente, para las otras formas de PIP (endometritis, salpingitis, pelviperitonitis, peritonitis) no poseen una representación categórica en imágenes. Es por ello que frente a la sospecha de alguna de estas formas de PIP, otros métodos diagnósticos adquieren mayor relevancia, tal es el caso del uso de la laparoscopía asociada a la toma de cultivos (20).
La TC muestra colecciones hipodensas, serpiginosas y de paredes engrosadas que realzan con contraste, como también identifica abscesos pelvianos de origen extra ginecólogico (26) (Figura 4C, D). Presenta además la capacidad de definir signos de peritonitis localizada o difusa. Si bien el estudio con TC o RM puede contribuir a la caracterización de una lesión anexial compleja de probable origen infeccioso, estos análisis no agregan mayor eficacia diagnóstica al cuadro ginecológico comparado con la ultrasonografía en casos agudos (Figura 4E). Sí aportan valor agregado en casos de evolución subaguda (incluyendo tuberculosis), PIP producido por gérmenes atípicos de crecimiento infiltrativo (actinomices) y en el diagnóstico diferencial de otros cuadros extra-ginecológicos, de naturaleza infecciosa o no, que pudiesen presentarse como un PIP (ej. plastrón apendicular, diverticulitis, peritonitis de origen no ginecológico) $(11,20,23,24)$.

l.c. Cuerpo lúteo hemorrágico. La presentación clínica de un quiste o cuerpo lúteo hemorrágico está dada por la aparición progresiva de dolor pelviano en la fase post-ovulatoria. Al examen físico puede haber dolor, empastamiento e incluso una lesión anexial palpable. En la EcoTV, el cuerpo lúteo hemorrágico clásicamente puede verse en su fase inicial como una lesión ovárica, unilateral, de predominio quístico, en cuyo interior se aprecia una fina malla reticular en "tela de araña" (Figura 5A). Posteriormente, al consolidarse el coágulo, es posible identificar al interior del quiste, una imagen ecogénica, en las porciones dependientes del quiste y de bordes cóncavos, la que se moviliza o flota en el interior al ser desplazada por el transductor (Figura 5B) (27). Al aplicar flujometría Doppler color se evidenciará sólo señal periférica en relación al quiste. Ante una lesión anexial, inicialmente de aspecto indeterminado, la evolutividad de la lesión al seguimiento ecográfico confirma la sospecha de cuerpo lúteo hemorrágico $(7,28)$. La tomografía computada puede orientar a un cuerpo lúteo hemorrágico, que se caracteriza por ser un quiste de menos de $3 \mathrm{~cm}$, de contenido denso, con paredes discretamente irregulares pero 
no engrosadas, asociado a la presencia de leve cantidad de líquido libre en la excavación pelviana, que puede tener densidad de sangre (26). La TC suele utilizarse en casos de dolor abdominal bajo o pélvico agudo inespecífico, especialmente cuando procesos de origen gastrointestinal son una consideración clínica posible (ej. apendicitis aguda), siendo la patología anexial un hallazgo del examen más que la sospecha clínica principal.

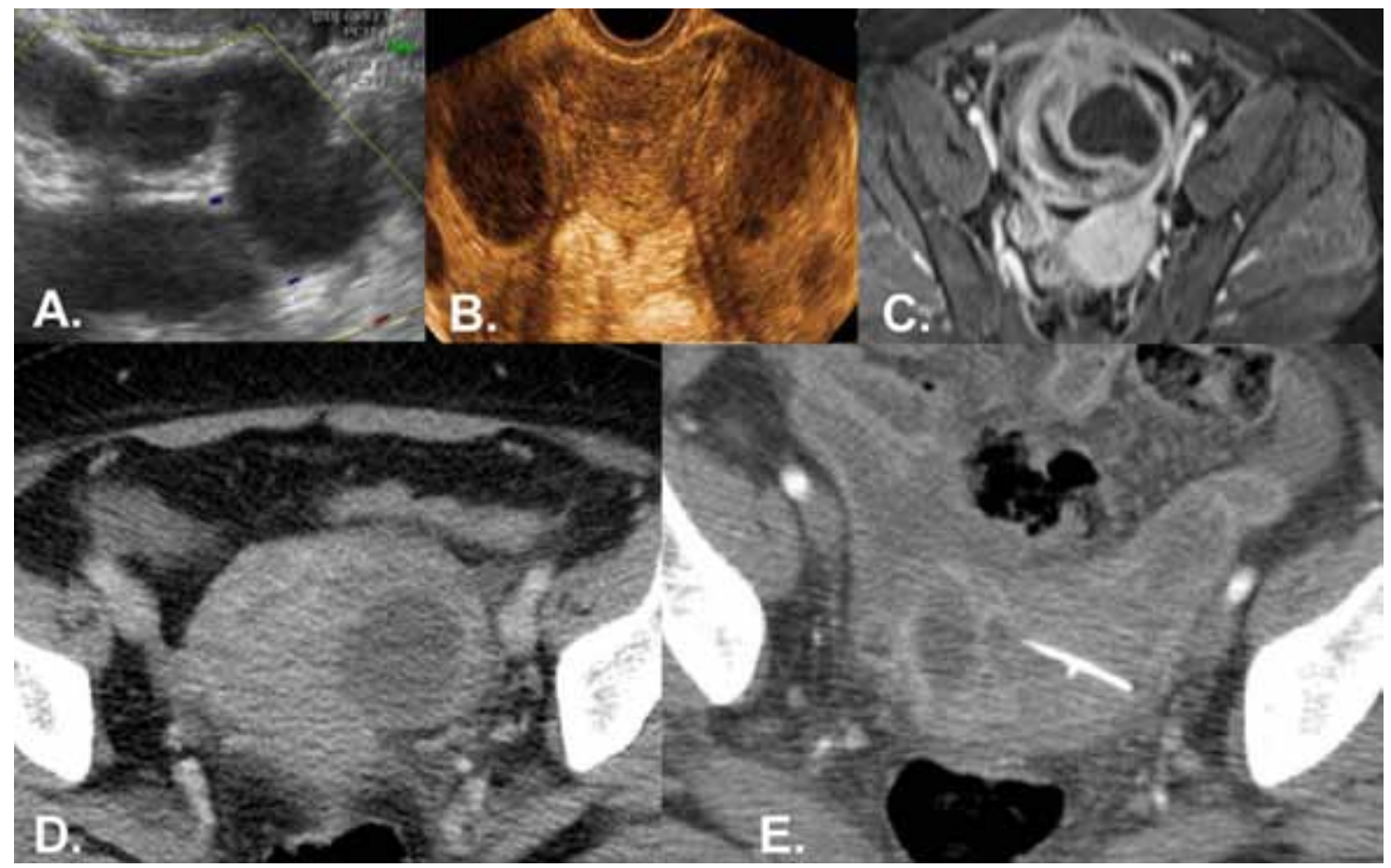

Figura 4. Proceso inflamatorio pelviano (PIP). Imágenes ultrasonográficas de piosalpinx $(A)$ y absceso tubo-ovárico (ATO), (B) en pacientes con cuadro clínico compatible con PIP. (C) Imagen de ATO en resonancia magnética. ( $D$ y E) Imagen de ATO y ATO roto en tomografía computada, nótese la presencia de un dispositivo intrauterino en la cavidad endometrial $(E)$.

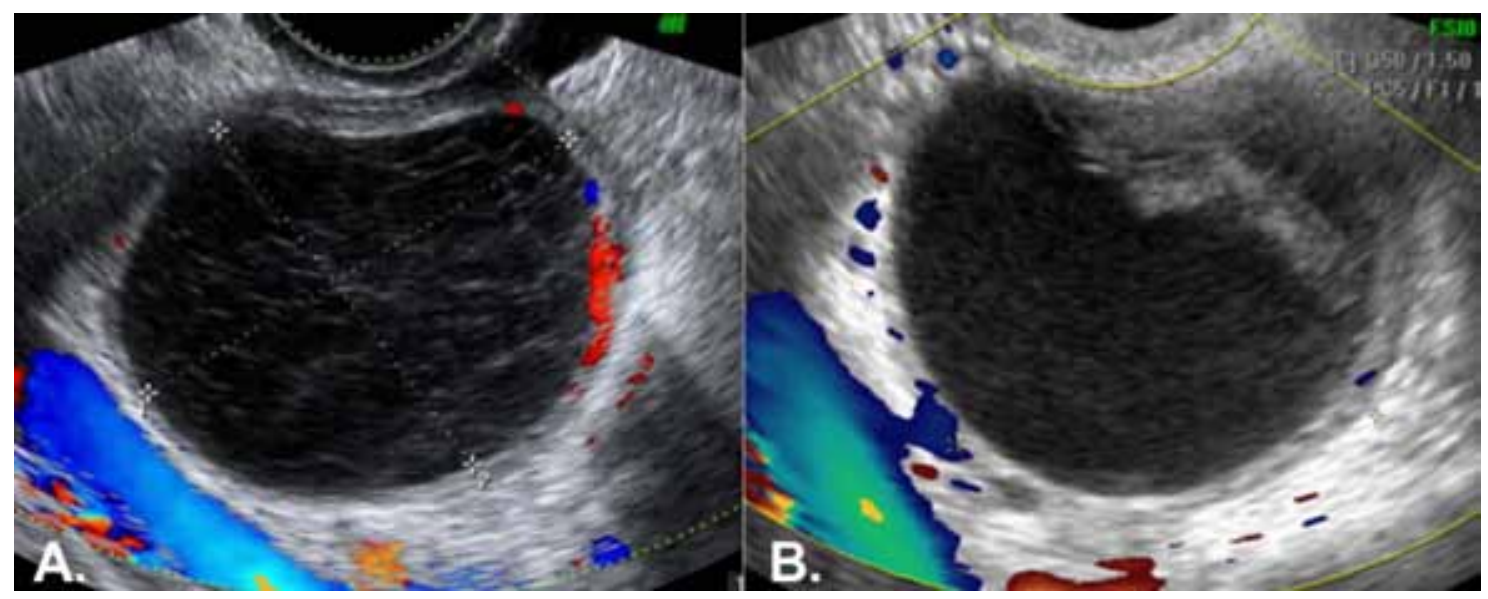

Figura 5. Quiste lúteo hemorrágico. Estudio ecográfico transvaginal con flujometría Doppler-color en pacientes con cuadros clínicos compatibles con quiste lúteo hemorrágico inicial $(A)$ y tardío $(B)$. 
I.d. Folículo roto sintomático. Al igual que con el cuerpo lúteo hemorrágico, el cuadro clínico se caracteriza por la aparición de dolor pélvico en otro momento del ciclo menstrual, a diferencia del cuerpo lúteo, este se presenta en el período peri-ovulatorio. Al examen se puede evidenciar dolor a la palpación de la región anexial, asociado o no a empastamiento y/o tumor anexial, y, al igual que el anterior, se debe plantear una vez descartado el embarazo. A diferencia del cuerpo lúteo hemorrágico, las imágenes ecográficas son menos específicas, por lo que ellas básicamente apoyarán la sospecha predominantemente clínica de esta entidad. En la EcoTV con estudio de Doppler color, es posible observar evidencias que apoyan la ocurrencia reciente de ovulación. Esto es, la presencia de una imagen estrellada en un polo ovárico, con reborde de color al Doppler (Figura 6A), asociada a la presencia de líquido peritoneal (de cuantía variable) en el fondo de saco de Douglas. Dicho líquido puede corresponder a líquido folicular o sangre vertida en la cavidad peritoneal. De tratarse de un hemoperitoneo, el líquido detectado contendrá áreas ecogénicas y heterogéneas, sugerentes de la presencia de coágulos en su interior (Figura $6 \mathrm{~B})(7,11,28)$.

l.e. Torsión anexial. La torsión anexial ocurre cuando el ovario gira sobre su pedículo vascular, comprometiendo el flujo sanguíneo a dicho ovario. Por lo general, se asocia a una masa anexial (50 a $75 \%$ de los casos), la que actuaría como polo de torsión, siendo el teratoma la etiología más frecuente. A diferencia de los dos cuadros anteriores, la torsión anexial puede presentarse en cualquier momento del ciclo menstrual, a cualquier edad, e incluso durante el embarazo. El dolor pélvico que le caracteriza es de inicio súbito e intenso y frecuentemente se asocia a nauseas y vómitos. Esta entidad representa sólo el 3\% de las urgencias ginecológicas. Sin embargo, su mayor incidencia es en mujeres jóvenes (85\% de los casos) y en edad fértil, por lo que un diagnóstico precoz permite una resolución quirúrgica conservadora (detorsión) con salvataje del anexo afectado (29). Desafortunadamente sólo entre el 30 y $56 \%$ de los casos existe la sospecha diagnóstica pre-operatoria (30). Del punto de vista imagenológico, los hallazgos ecográficos dependerán del tiempo de evolución que tenga la torsión. Lo más frecuente es encontrar un ovario aumentado de tamaño producto del edema o congestión ( $80 \%$ de los casos, Figura 7A). Cuando existe señal tanto arterial como venosa, en el estudio con Doppler color, se espera encontrar ovarios viables en más del $90 \%$ de los casos. A su vez, la ausencia de señal Doppler venosa y arterial se asocia a daño isquémico con necrosis ovárica hasta en un $85 \%$ de los casos (30). Ante la sospecha clínica de torsión anexial, uno de los signos ecográficos que apoya dicho diagnóstico es la presencia de un "remolino" vascular en relación al pedículo ('whirpool sign') (Figura 7B), cuya imagen obedece al enrollamiento del pedículo vascular sobre su eje) (31). Aunque los valores predictivos para este signo ecográfico parecen ser buenos, su detección es claramente operador dependiente y su presencia depende del tiempo de evolución y de la cantidad de vueltas sobre su eje que la torsión tenga. Adicionalmente, algunos autores han propuesto graduar este hallazgo, dependiendo de si existe flujo arterial y/o venoso al interior del área "enrollada" (32). A fin de lograr un diagnóstico precoz, que permita un manejo activo y conservador, algunos autores han establecido que el signo más precoz y de mayor utilidad diagnóstica es la ausencia de flujo venoso normal en el pedículo vascular ovárico. En manos entrenadas, este signo tiene valores de sensibilidad y especificidad que bordean el $100 \%$ y $97 \%$, respectivamente (33). En TC y RM se pueden detectar hallazgos inespecíficos para torsión anexial, como el aumento de tamaño del ovario (habitualmente por la masa asociada), la desviación del útero hacia el lado afectado y la ascitis (34). La certeza diagnóstica de la tomografía computada es algo inferior a la del US para torsión anexial (26). En casos donde exista gran distorsión de la anatomía pélvica por una masa anexial predisponente, especialmente cuando ocurre desplazamiento cefálico que aleje los anexos del campo visual de la EcoTV, la TC es útil para detectar congestión del mesoovario torcido y el remolino vascular permitiendo un diagnóstico especifico de torsión (Figura 8A) (34). La RM se ha utilizado en este mismo escenario clínico en pacientes embarazadas con sospecha de torsión anexial cuando los ovarios han sido desplazados de su posición original por el útero grávido (35). La RM es además particularmente útil para caracterizar variantes "infantiles" de torsión que puedan ocurrir en este contexto, sin masa predisponente, identificando el edema y/o hemorragia del estroma ovárico asociado al desplazamiento periférico de los folículos (Figura 8B). Tanto la TC como la RM pueden contribuir con la caracterización de la lesión anexial responsable de la torsión (34).

I.f. Contribución de la TC y RM al diagnóstico diferencial de las urgencias ginecológicas. En la actualidad, para la mayoría de las urgencias ginecológicas la EcoTV debiese bastar para establecer un diagnóstico correcto de la entidad causal. Sin embargo, el dolor referido por la paciente puede ser inespecífico y el clínico sospechar otras causas de dolor abdominal y solicitar una TC de abdomen y pelvis para esclarecer el diagnóstico.

La utilidad de la TC en urgencias ginecológicas es el diagnóstico diferencial de condiciones extra ginecológicas de presentación similar con alguna de las condiciones antes mencionadas. Tal es el caso de la apendicitis aguda que se puede 
confundir con un PIP o la litiasis urinaria que puede remedar el dolor pélvico agudo generado por una torsión anexial (34). Frente a cuadro clínico sugerente, la TC y el PieloTAC permiten confirmar o descartar la presencia de compromiso inflamatorio apendicular o de un cálculo en la vía urinaria, respectivamente $(10-13,36,37)$. La RM, comparativamente con los exámenes anteriores, no aporta elementos diagnósticos adicionales en la toma de decisiones, es más costosa y toma más tiempo, por tanto, no se justifica su solicitud cuando se enfrenta a una urgencia ginecológica en que existe duda diagnóstica. Dado que la RM no utiliza radiación ionizante, su uso en pacientes embarazadas con abdomen agudo ha ido tomando un rol cada vez más preponderante, especialmente para la detección de apendicitis aguda (38). Además permite una buena caracterización de patología anexial aguda cuando los ovarios se encuentren desplazados de su posición pélvica habitual por el útero grávido (35).

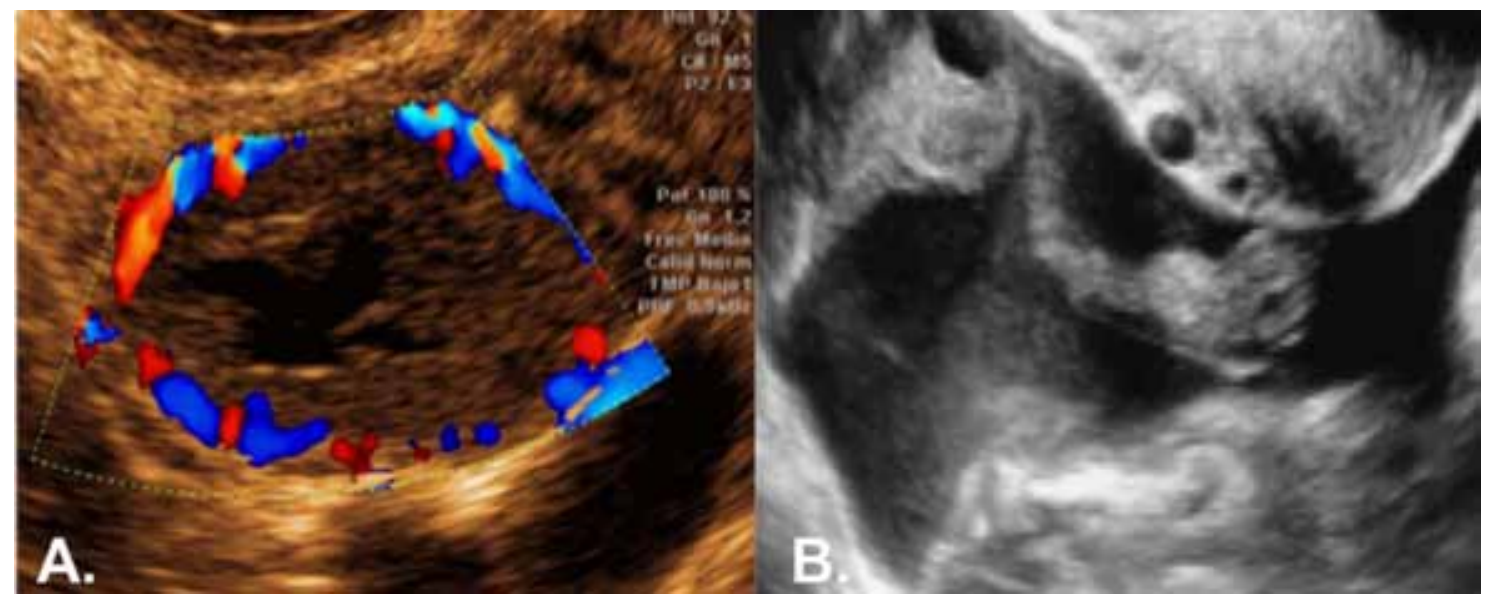

Figura 6. Quiste roto. (A) Ecografía transvaginal con flujometría Doppler mostrando imagen de quiste estrellado en polo ovárico con señal vascular periférica, sugerente de cuerpo lúteo. (B) Imagen de líquido libre en fondo de saco de Douglas, con áreas sólidas heterogéneas compatibles con coágulos organizados (hemoperitoneo).

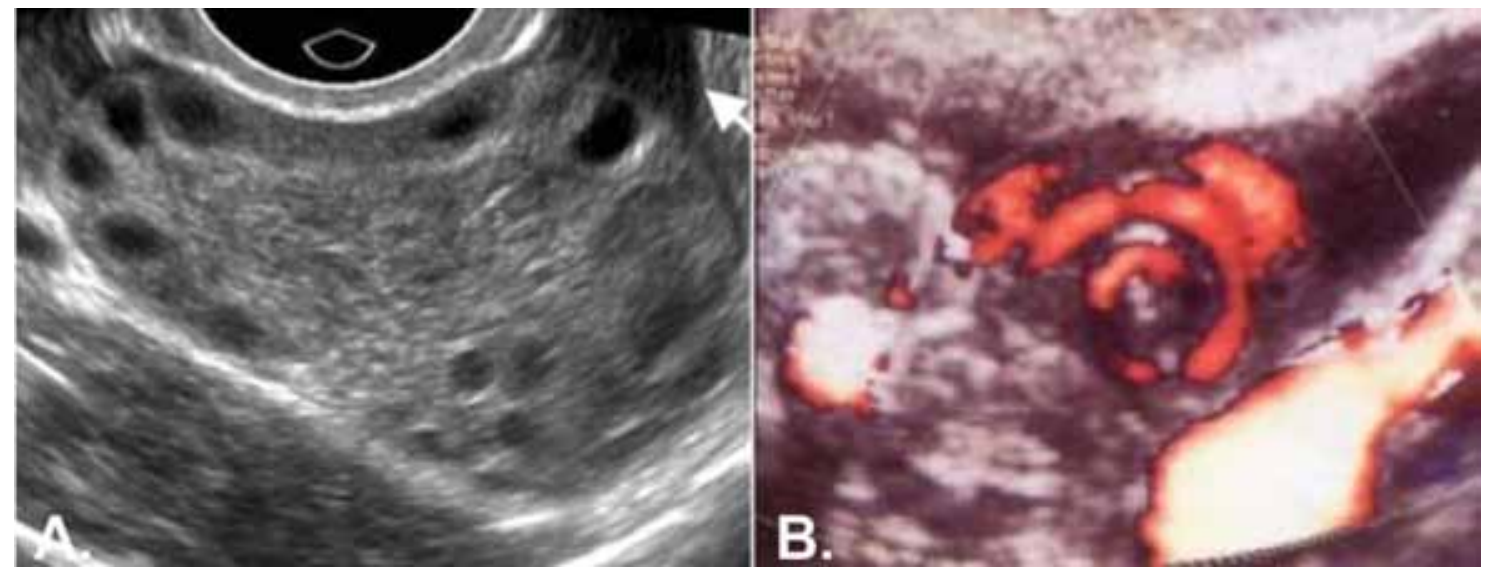

Figura 7. Torsión anexial. (A) Estudio ecográfico transvaginal que muestra ovario aumentado de volumen por edema secundario a un cuadro clínico sugerente de torsión anexial. (B) EcoTV con flujometría Doppler mostrando "signo del remolino" (whirlpool sign) en paciente con torsión anexial. 


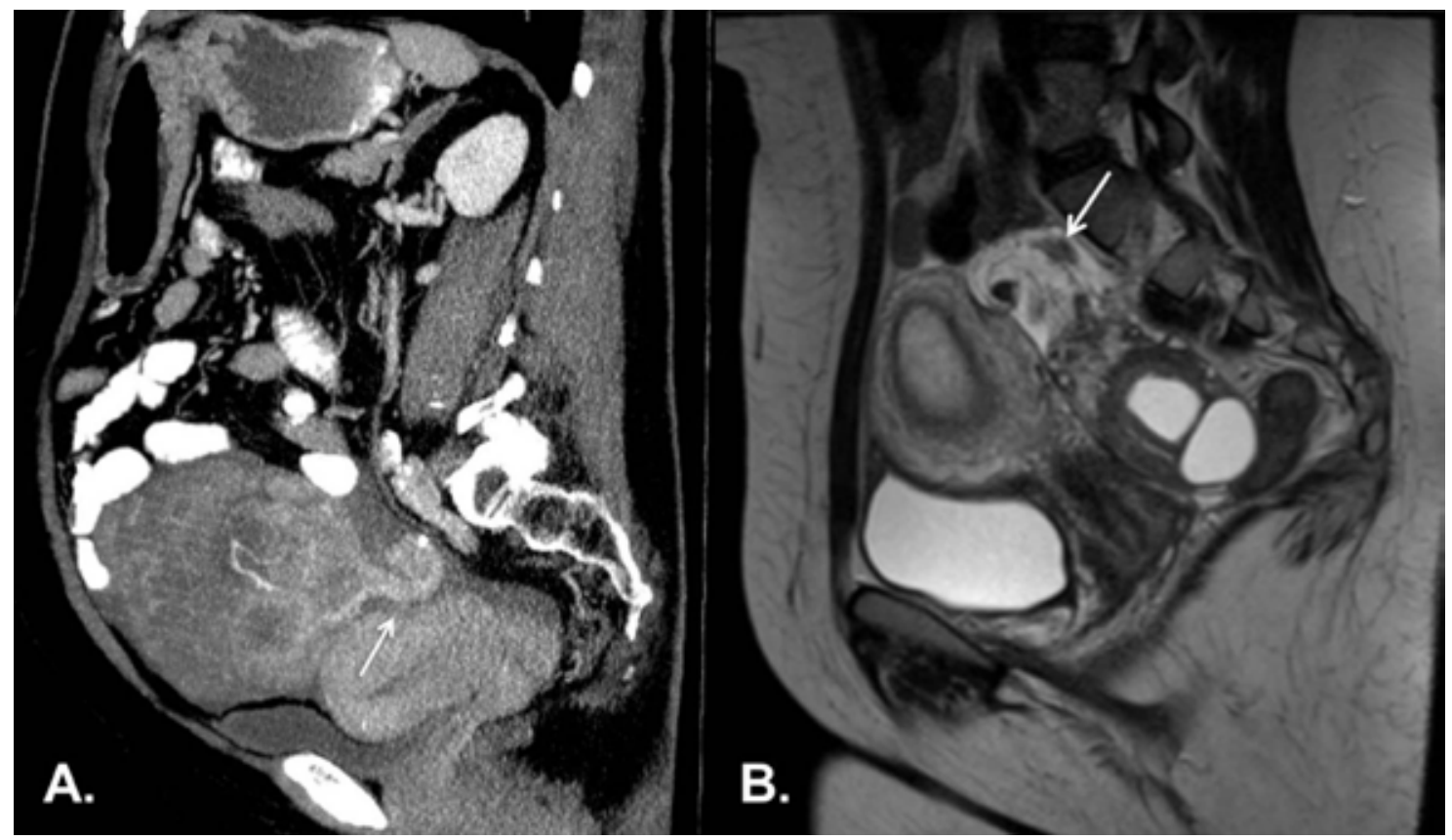

Figura 8. Torsión anexial en CT y RM. Corte sagital de una TC de abdomen y pelvis (A) donde se observa una torsión anexial secundaria a la presencia de una lesión sólida. Corte sagital de una RM de pelvis ponderada en T2 en una paciente embarazada con dolor abdominal (B), el examen demuestra al ovario derecho aumentado de volumen, con múltiples folículos periféricos y un quiste en su polo inferior. En ambas imágenes se observa con claridad el pedículo vascular torcido (flechas).

\section{Patología uterina benigna}

Las enfermedades del miometrio y endometrio pueden ser diagnosticados con un alto grado de certeza tanto por la EcoTV, como con el uso de TC o RM.

II.a. Mioma uterino. La visualización ecográfica de los miomas uterinos (Figura 9A, B), en todas sus variedades, permite su caracterización en cuanto a su tamaño, número, ubicación general, relación con el endometrio, vascularización, etc. (39). Los índices diagnósticos de la ecografía en miomatosis uterina muestran: sensibilidad $87 \%$, especificidad $89 \%$, LR(+) de 8 y LR(-) de 0,15 (12) (7). La RM mejora la capacidad de localización exacta de los miomas y su relación con la cavidad endometrial (Figura 9C), como también permite conocer su comportamiento en relación al flujo vascular arterial. Estos elementos de caracterización son indispensables en la planificación del manejo quirúrgico y/o endovascular de algunas condiciones particulares. Entre estas situaciones destaca la presencia de miomas grandes extra pelvianos, miomas múltiples con deseo de paridad y control post-operatorio en cirugía conservadora (40-43). Uno de los usos más frecuentes de la RM es la diferenciación de miomas subserosos pediculados de masas anexiales sólidas, especialmente cuando existe distorsión de la anatomía pélvica y uno o ambos ovarios no hayan podido ser detectados en el estudio de EcoTV. En pacientes con miomas complicados por degeneración hemorrágica, tanto la TC como la RM logran una caracterización adecuada de esta patología, siendo la RM el examen de elección para confirmar este diagnóstico en pacientes embarazadas (Figura 10) (35). 


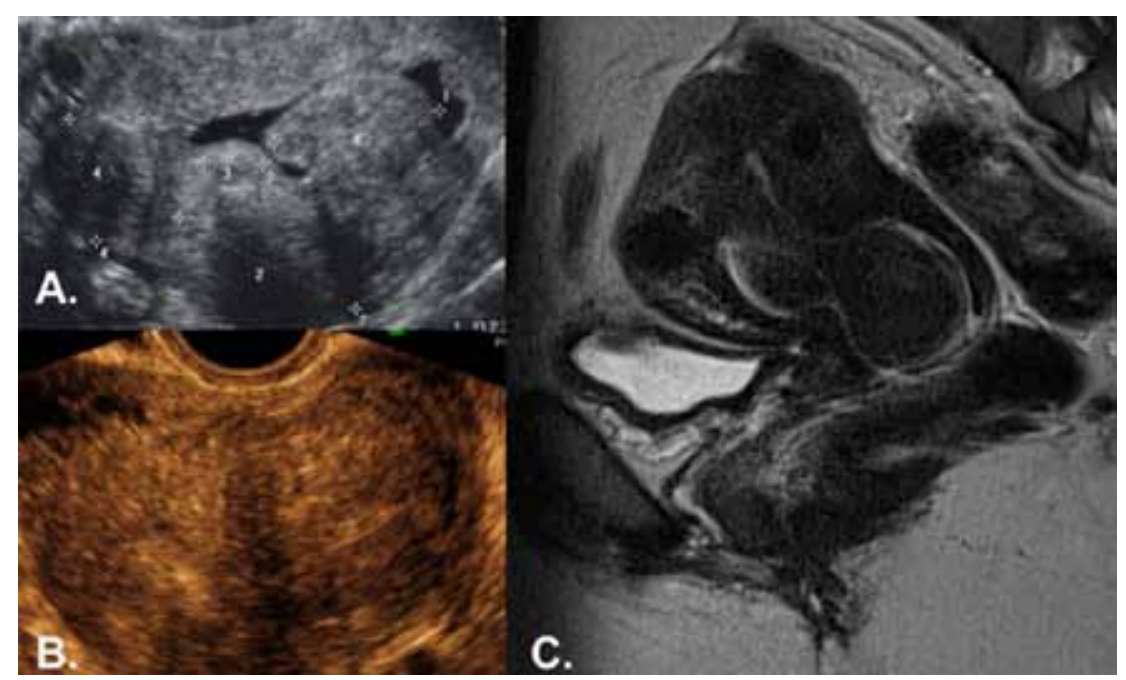

Figura 9. Miomatosis uterina. Ecografía transvaginal de miomatosis uterina múltiple $(A)$ y mioma transmural solitario de gran tamaño (B). (C) Corte sagital de RM de pelvis femenina en paciente con diagnóstico de miomatosis uterina múltiple, incluyendo mioma pediculado en proceso de expulsión a través de canal cervical.

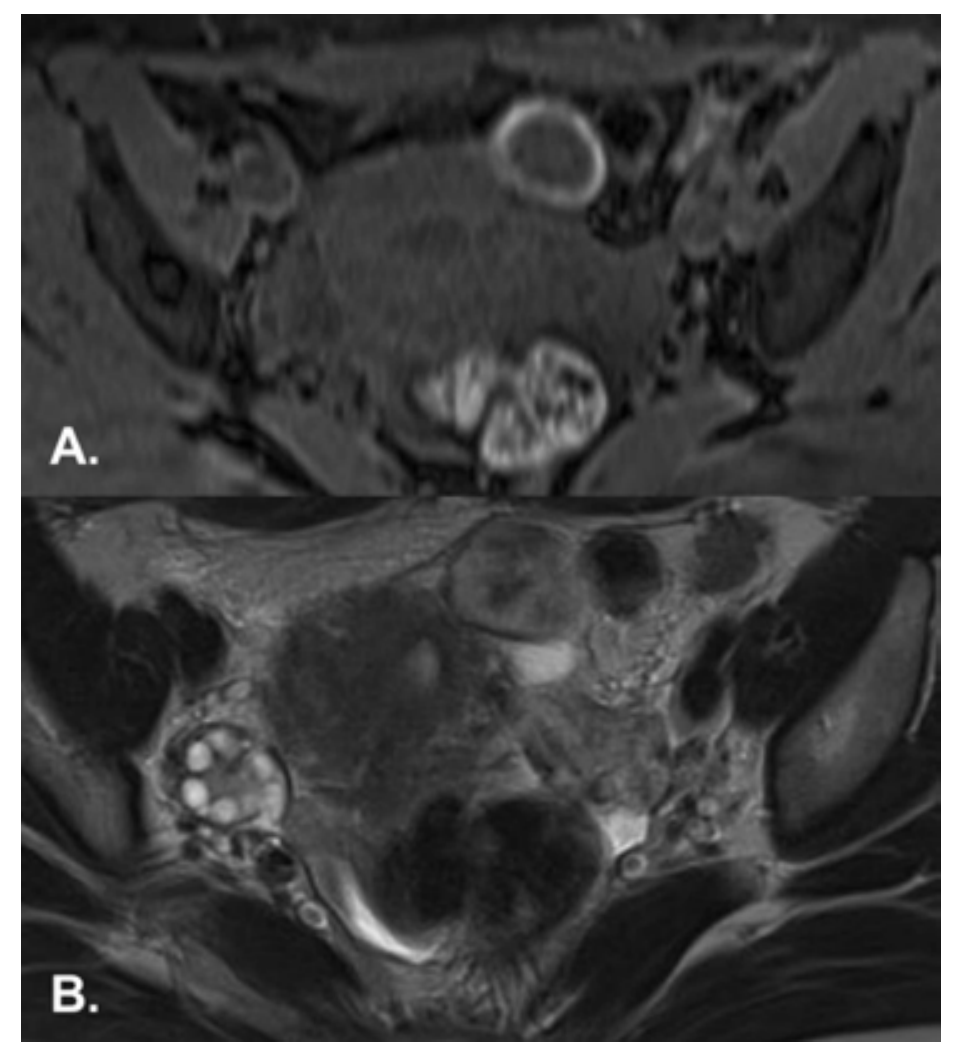

Figura 10. Mioma con degeneración hemorrágica por RM. Corte axial de una RM de pelvis ponderada en T1 (A) donde se observa un mioma subseroso en la pared anterior del útero que presenta un halo hiperintenso. Este mioma demuestra señal intermedia en secuencias ponderadas en T2 (B), compatible con un mioma subseroso con degeneración hemorrágica. 
II.b. Adenomiosis. Patología de alta prevalencia (27-50\%) y difícil diagnóstico. Habitualmente se subdiagnostica, estimándose que más del $60 \%$ de los casos son hallazgos de la anatomía patológica. La ecografía es una técnica de resultado discreto, con diversos elementos de sospecha que tienen una baja capacidad diagnóstica. Los criterios de sospecha ecográfica actuales son: aumento globuloso difuso del útero en ausencia de miomatosis, estrías perpendiculares subendometriales, quistes subendometriales (Figura 11A), miometrio heterogéneo (44).

La RM mejora ostensiblemente el rendimiento diagnóstico en adenomiosis en comparación con la ecografía. Los elementos que sugieren esta patología en la RM son: engrosamiento $>10 \mathrm{~mm}$ de la zona de unión endometrio-miometrial, focos hemorrágicos subendometriales y estrías radiales subendometriales hiperintensas en T2 (Figura 11B, C) (45).

Los índices diagnósticos de la RM en adenomiosis muestran: sensibilidad $78-88 \%$ y especificidad $67-93 \%$. Además de detectar variantes habituales de adenomiosis, la RM es muy útil en la caracterización de adenomiomas intramiometriales y diferenciarlos de leimiomas: son habitualmente alargados, de bordes mal definidos, continuos con la zona de unión endometrio-miometrial, con islote de endometrio central hemorrágico (Figura 12) (46).

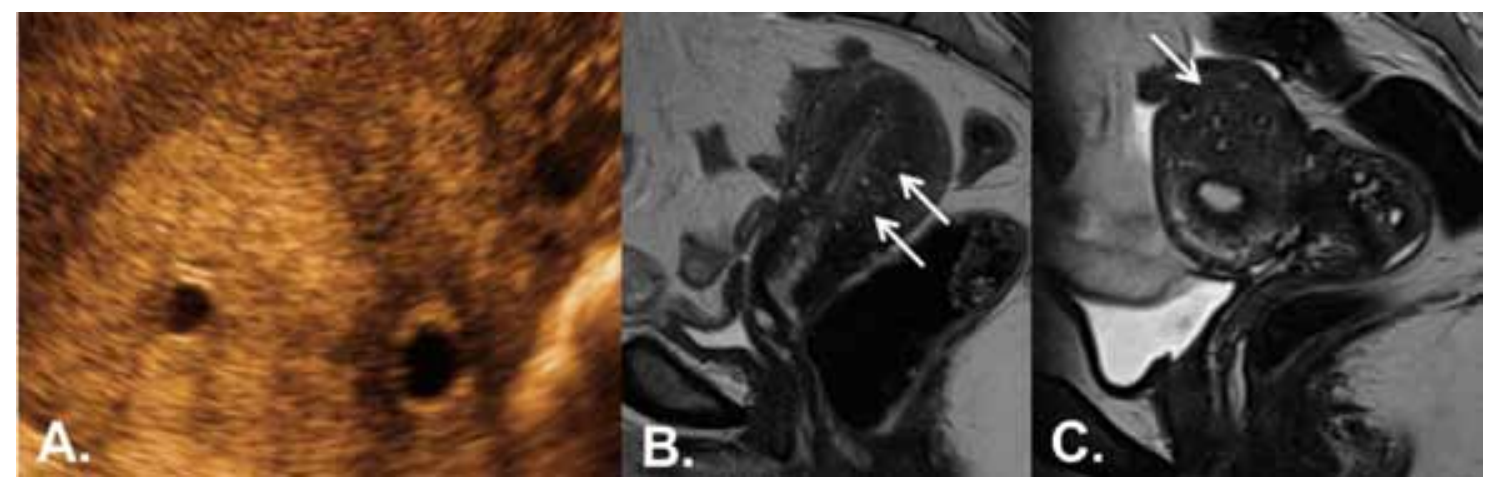

Figura 11. Adenomiosis uterina. (A) Ecografía transvaginal que muestra quistes subendometriales en paciente con adenomiosis. (B) Imagen de adenomiosis uterina difusa en la resonancia magnética, las flechas indican zona de engrosamiento subendometrial. (C) Adenomiosis focal en resonancia magnética, donde se observa un área focal de ensanchamiento de la zona de unión en el fondo uterino con múltiples focos hiperintensos en T2 (flecha).

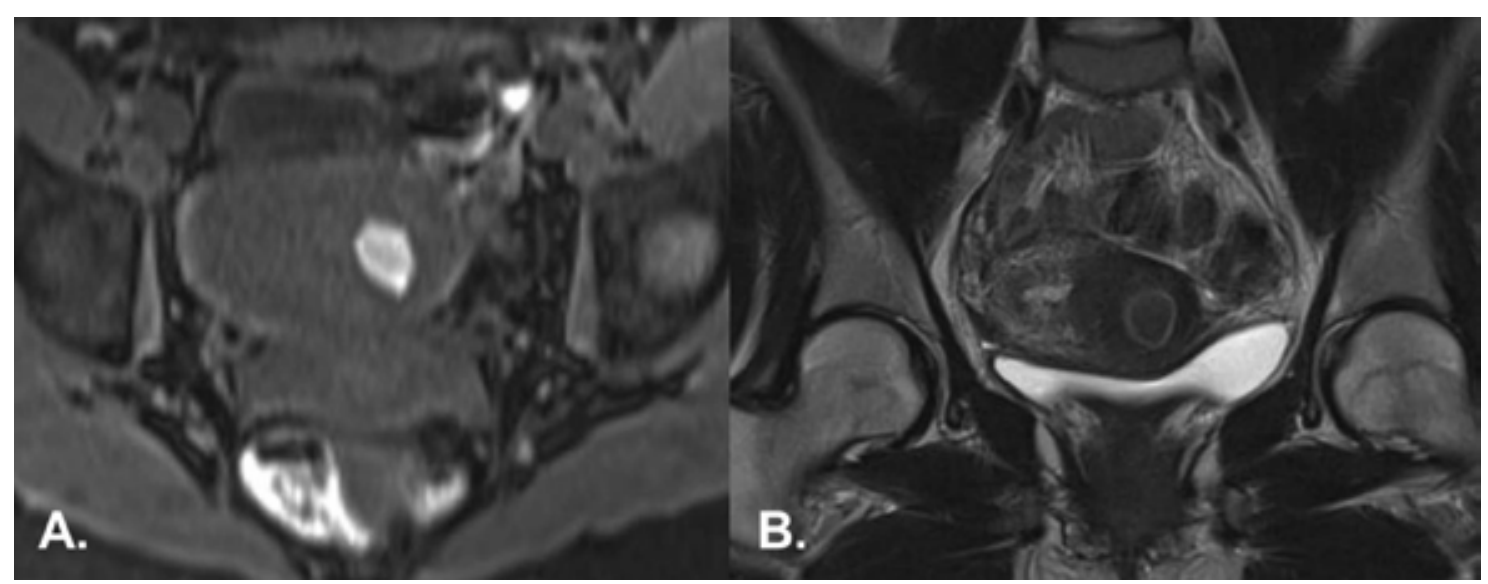

Figura 12. Adenomioma intramiometrial en RM. Corte axial ponderado en T1 de una RM de pelvis (A) observando foco redondeado hiperintenso en el espesor del miometrio consistente con área de hemorragia recurrente. Corte coronal de una RM de pelvis en la misma paciente, ponderado en T2 (B), confirma lesión redondeada hipointensa en miometrio con foco central de señal intermedia a baja ("shading") que corresponde al área hemorrágica en T1. 
II.c. Patología endometrial. El endometrio puede ser caracterizado con mayor precisión utilizando EcoTV y RM. La TC no juega un rol importante en la caracterización endometrial aunque puede definir su espesor al ser medido en reconstrucciones sagitales de alta calidad. La EcoTV y RM pueden clasificar las variedades de endometrio según el momento del ciclo menstrual, así como también sus patologías más comunes (Figura 13). La EcoTV presenta ventajas evidentes por su proximidad al órgano y la buena resolución proximal de los transductores endoluminales $(7,5 \mathrm{mHz})(47)$.

II.c.1. Engrosamiento endometrial. Se refiere a que el grosor de ambas capas endometriales esté sobre el límite estimado para condiciones como la edad, fase del ciclo menstrual, hormonoterapia, etc. (4,47-49). En la edad fértil y en ausencia de anticonceptivos orales, el endometrio puede llegar hasta $12 \mathrm{~mm}$ en la fase secretora, bajando hasta 2 a $3 \mathrm{~mm}$ en la menstrual. En la post-menopausia sin metrorragia el grosor debe ser menor que $7 \mathrm{~mm}$, con o sin uso de $\mathrm{TRH}$, ya sea ésta combinada o secuencial. Con metrorragia debe medir menos de $5 \mathrm{~mm}$ (50). Fuera de estos parámetros, se considerará un endometrio anormalmente engrosado. Esta situación amerita un mayor estudio etiológico, orientado a la búsqueda de lesiones endometriales focales, hiperplasia endometrial o neoplasias malignas (4,47-49).

II.c.2. Lesiones focales endometriales. Las lesiones focales endometriales más frecuentes son los pólipos y los miomas submucosos.
Aproximadamente un $20 \%$ de los pólipos no son visibles a la ultrasonografía convencional. Se presentan como un nódulo hiperecogénico, bien delimitado, que no afecta la unión endometriomiometrial y que abomba la línea media entre las capas endometriales (Figura 14A) (51). Con el estudio Doppler color se puede ver un vaso central único que discurre por el pedículo del pólipo (52).

Los miomas submucosos se presentan a la ecografía como una lesión redondeada, hipoecogénica y con un límite poco definido con el miometrio. Estos miomas comprometen en forma variable la línea endometrial, desplazándola hacia el interior de la cavidad (Figura 14B). El estudio Doppler color evidencia un patrón vascular en "canasta" con varios vasos predominantemente periféricos. Es conveniente describir en detalle el porcentaje del mioma que protruye a la cavidad, pues ayuda a programar el procedimiento quirúrgico a realizar $(53,54)$.

En el estudio de los pólipos endometriales, la RM no presenta mayor ventaja diagnóstica respecto a la EcoTV. Ante la duda es preferible realizar un estudio ultrasonográfico transvaginal previa instilación de suero fisiológico a la cavidad uterina (histerosonografía) (55) o también una histerosalpingografía. La RM puede jugar un rol en la evaluación preoperatoria de engrosamientos endometriales que tengan diagnóstico confirmado de neoplasia, especialmente cuando se desea evaluar la posibilidad de infiltración tumoral de las capas miometriales más profundas (Figura 14C).

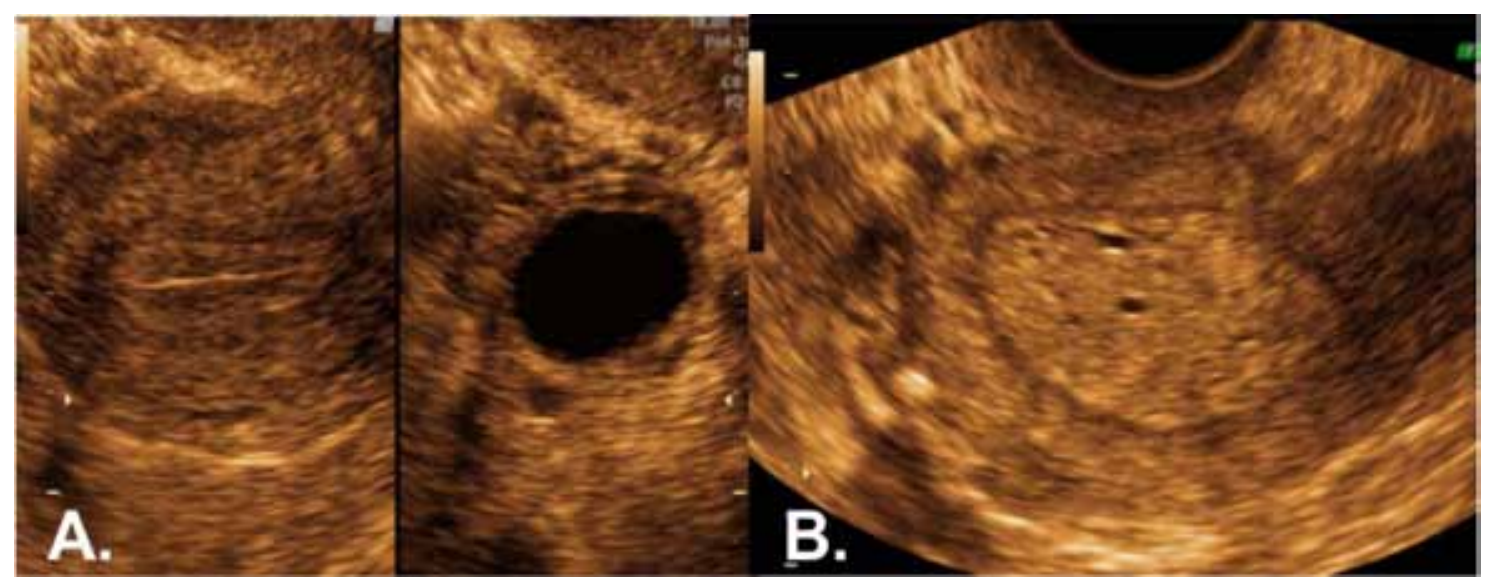

Figura 13. Endometrio. (A) Estudio ecográfico transvaginal de endometrio normal en fase proliferativa tardía (mitad izquierda muestra endometrio homogéneo tri-laminar pre-ovulatorio y mitad derecha muestra folículo pre-ovulatorio). (B) Imagen de endometrio heterogéneo engrosado que pudiera incluir una lesión focal. 


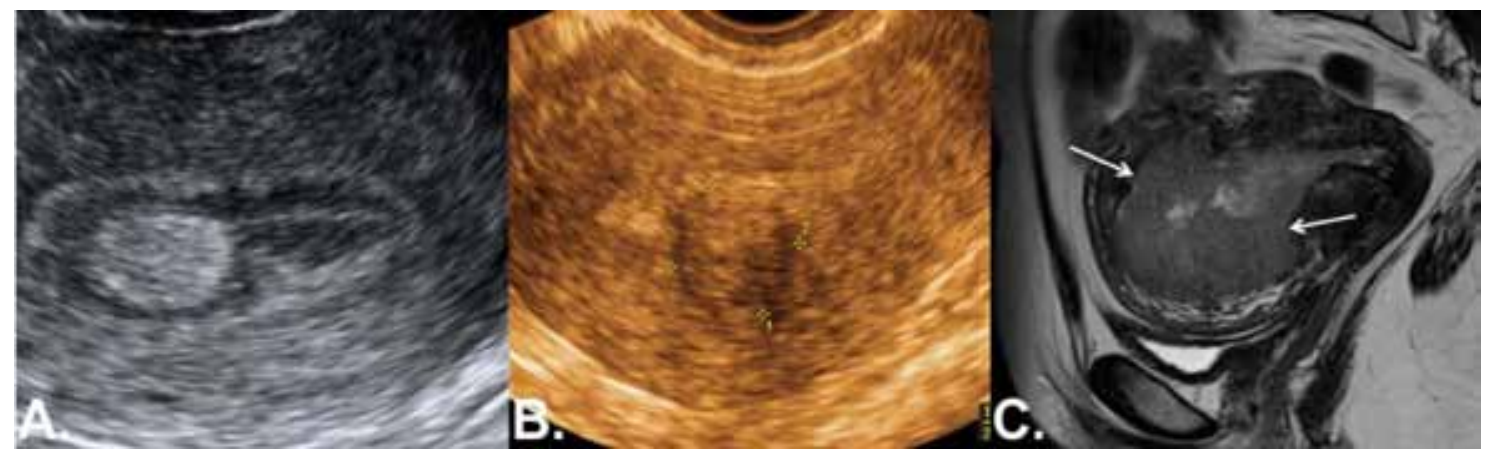

Figura 14. Lesiones focales endometriales. Ecografía transvaginal de endometrio engrosado con probable pólipo endometrial (A) y mioma submucoso (B). (C) Corte sagital de pelvis femenina en paciente con diagnóstico de cáncer de endometrio con invasión miometrial (flecha).

En el estudio de miomas, la RM puede establecer con seguridad la relación exacta de un mioma submucoso con el endometrio, la ubicación del pedículo, su espesor y el grado de vascularización asociado (Figura 15). Esto es relevante desde el punto de vista de la planificación de una cirugía conservadora, en una paciente con deseos de fertilidad (56).

II.d. Malformaciones uterinas. Generalmente una malformación uterina se sospecha en una ecografía convencional (Figura 16A), pero la caracterización definitiva debe ser realizada por RM $(57,58)$. Esta técnica (Figura 16B) tiene una sensibilidad de aproximadamente un $98 \%(7,59,60)$. Su fortaleza radica en la capacidad definir con precisión el contorno uterino fúndico y la relación de éste con la cavidad endometrial subyacente, ya sea formando un tabique (útero septado) o bien una hendidura (útero bicorporal). Además entrega información del cérvix y de posibles tabiques vaginales asociados. La EcoTV en 3 dimensiones (EcoTV3D) presenta una eficacia diagnóstica superior al 93\% (Figura 16C), sin embargo su accesibilidad también es limitada (61-63). El 'gold standard' es la histeroscopia y laparoscopia diagnóstica, con $100 \%$ de especificidad (63-65).

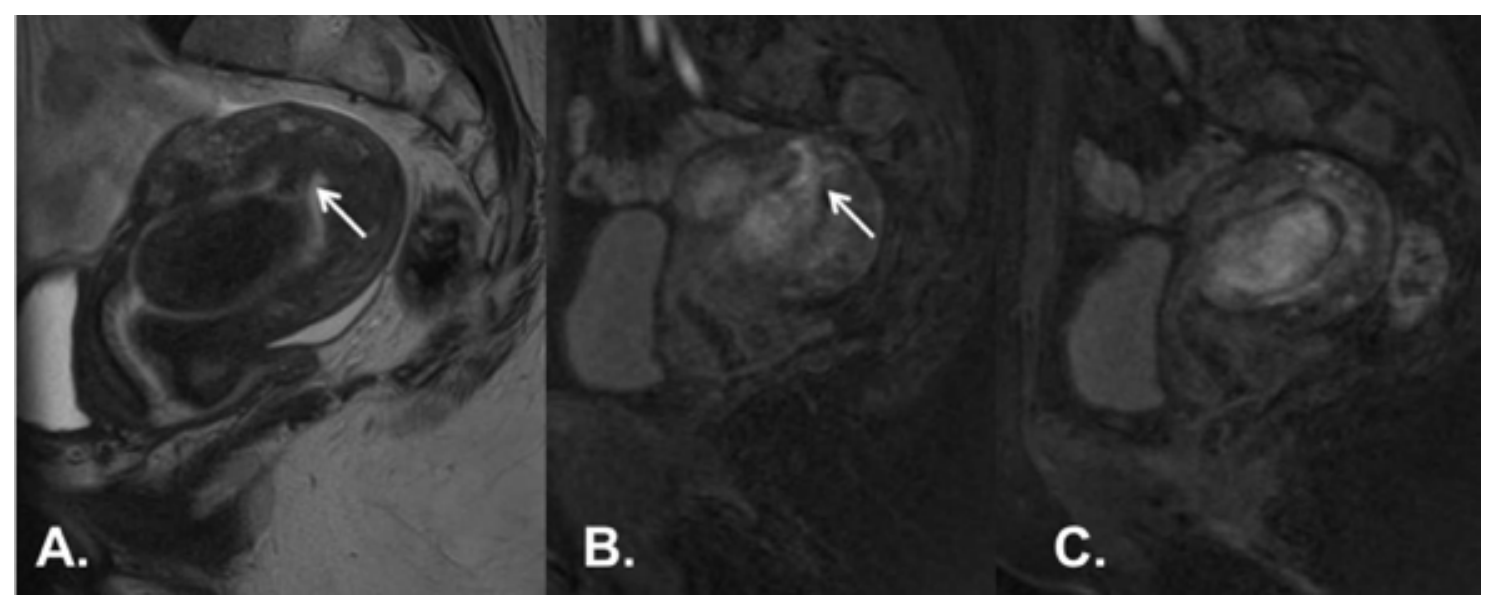

Figura 15. Caracterización de mioma submucoso en RM. Cortes sagitales de RM de pelvis donde se observa ensanchamiento de la cavidad endometrial secundario a la presencia de un mioma submucoso pediculado. El pedículo es claramente evidente en la secuencia ponderada en T2 dependiente del fondo (A, flecha). En las secuencias contrastadas se observa que el pedículo es vascular (B, flecha) y que el mioma realza de manera ávida con gadolinio $(\mathrm{C})$. 


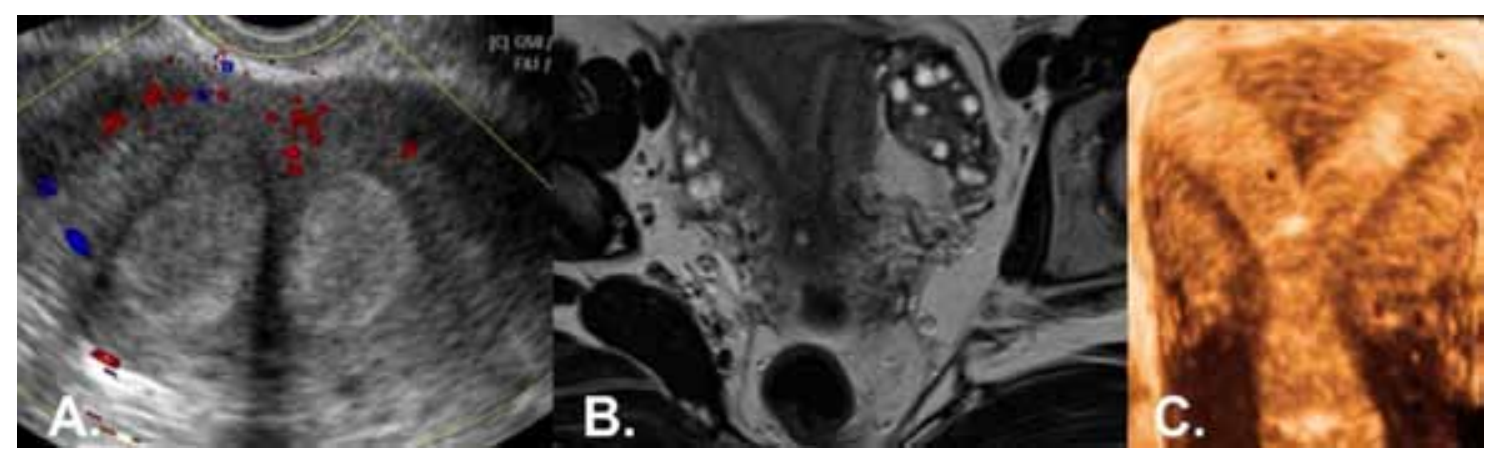

Figura 16. Malformaciones uterinas. Imagen de ecografía transvaginal de dos cavidades endometriales hacia el fondo uterino (A). Útero septado en RM (B) o EcoTV en 3 dimensiones (C) demuestran tabique muscular.

\section{Patología anexial benigna}

Hasta el $10 \%$ de las mujeres, presentarán en alguna etapa de su vida una lesión ovárica o paraovárica (66). Existe consenso en que el US es la técnica de elección en su diagnóstico, tanto en su pesquisa inicial como en su caracterización definitiva (67-68).

Las imágenes complementarias (TC y RM) mejoran el diagnóstico de las lesiones anexiales en algunos casos particulares. Especialmente en aquellos tumores de gran volumen, de carácter incierto a la ultrasonografía y en pacientes con sospecha de endometriosis profunda o de pared abdominal, el estudio con TC o RM es imprescindible para un manejo adecuado (69-74).

\section{III.a. Quiste ováricos.}

III.a.1. Quiste simple. Imagen hipoecogénica, homogénea, de paredes finas, lisas y con refuerzo acústico posterior. Sin nódulos, tabiques ni contenido ecogénico en su interior (Figura 17A). Con estudio Doppler color se observa sólo vascularización periférica escasa. El estudio con imágenes adicionales como la RM (Figura 17B) o TC se hace necesario cuando el quiste excede los límites de ventana de la ecografía convencional $(75,76)$ con el fin de descartar la presencia de un componente sólido que cambien el diagnóstico a un quiste complejo.

III.a.2. Quiste mucinoso. Imagen habitualmente grande, sobre $10 \mathrm{~cm}$ de diámetro, con contenido líquido de ecogenicidad intermedia y homogénea (Figura 17C). Presenta múltiples tabiques finos, sin nódulos en su interior. Por su tamaño, muchas veces el quiste mucinoso excede la pelvis y debe ser mejor caracterizado con RM o TC (Figura 17D) $(76,77)$.

III.a.3. Teratomas. Los teratomas ováricos son la neoplasia ovárica mas frecuente. Estos tumores de crecimiento lento están compuestos con elementos celulares maduros de al menos dos de las tres líneas germinales. Por ende, la apariencia de los teratomas en las distintas técnicas imagenológicas depende de los tejidos que la componen y su porcentaje. En EcoTV los teratomas se observan como tumores complejos, sólido-quísticos, con nódulos ecogénicos redondeados y otras zonas con imágenes reticulares ('dermoid mesh') (Figura 18A). Ocasionalmente se aprecian focos calcificados con sombra acústica posterior y vascularización periférica al estudio Doppler color (78). En general el estudio con TC o RM confirma el diagnóstico de un teratoma (Figura 18B, C), dada la excelente resolución de contraste entre los distintos componentes del teratoma; líquido, sebáceo (densidad o señal de grasa) y calcio $(79,80)$. La TC es de utilidad en la caracterización de teratomas complicados con rotura identificando signos específicos de peritonitis química que incluyen lóculos nodulares con densidad de grasa distribuidos a través de la cavidad peritoneal (Figura 19). 


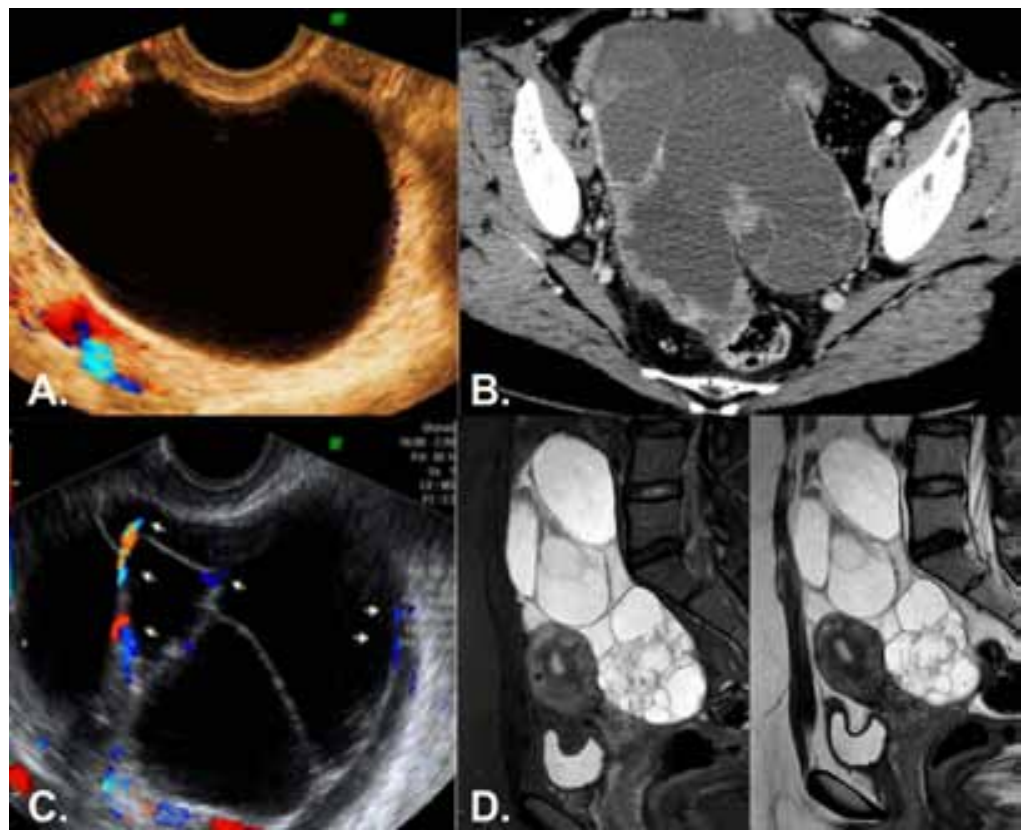

Figura 17. Lesiones quísticas ováricas. Comparación entre un quiste simple y una neoplasia ovárica serosa (A y B, ecografía transvaginal y tomografía computada, respectivamente) y un quiste y una neoplasia ovárica mucinosa ( $C$ y D, ecografía transvaginal y resonancia magnética STIR y T2, respectivamente).

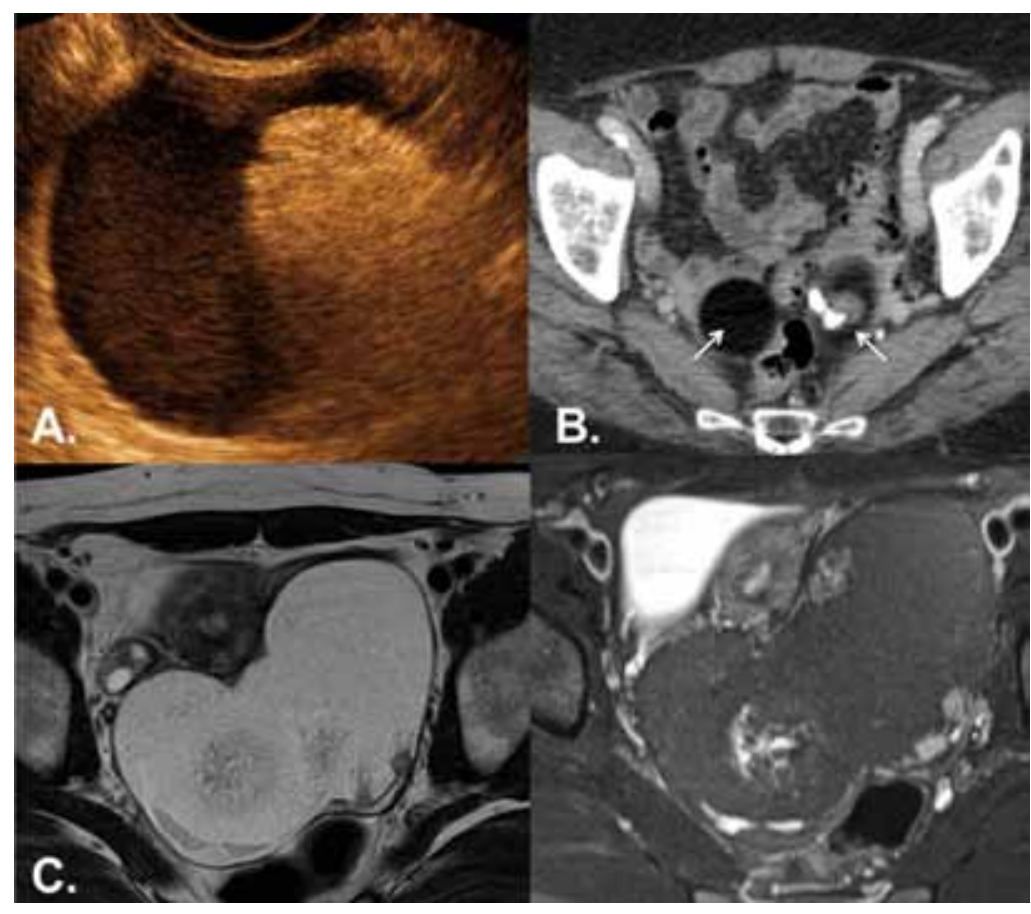

Figura 18. Teratomas anexiales. Comparación de un teratoma entre las distintas técnicas de imagen; ecografía transvaginal (A), resonancia magnética en secuencias ponderadas en T2 (B), sin y con saturación grasa, y tomografía computada (C), donde el hallazgo es bilateral (flechas). 


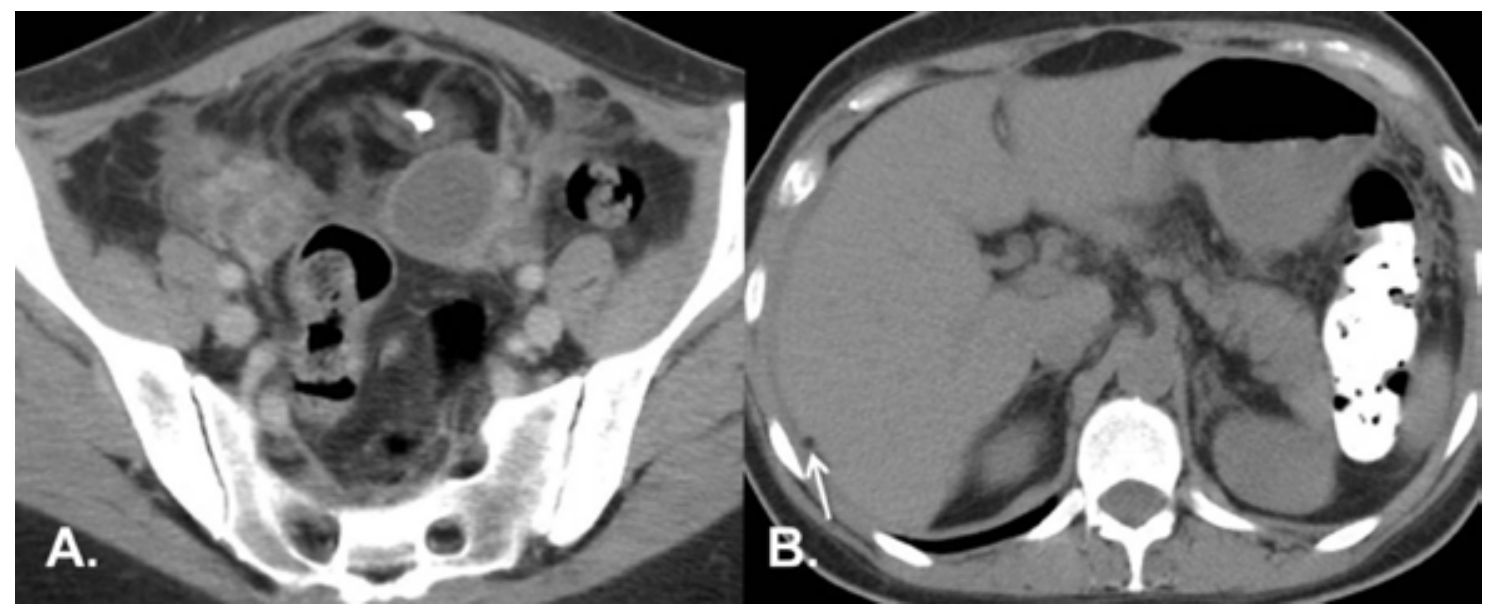

Figura 19. Teratoma complicado. Corte axial de TC con (A) y sin contraste (B). En la pelvis se observa una lesión anexial izquierda con componente líquido, graso y una calcificación gruesa, con los caracteres de un teratoma. Este presenta además signos de rotura con ascitis, cambios inflamatorios peritoneales y foco adiposo (sebáceo) en situación perihepática derecha ( $B$, flecha).

III.a.4. Endometriosis ovárica. Tanto la EcoTV como la TC tienen baja especificidad en el diagnóstico de endometriomas (26). La resonancia magnética, con sus secuencias susceptibles a la detección de productos de degradación de la hemoglobina es altamente sensible y específica. Los endometriomas se presentan como un quiste de marcada hiperseñal en T1 producto de hemorragia recurrente, asociado a baja señal en T2 (efecto "shading"). En ecografía, el $72 \%$ de los casos, se observa la imagen típica de un quiste de contenido denso, en "vidrio esmerilado", con una especificidad diagnóstica cercana al $100 \%$ (Figura 20A). En el otro $28 \%$, la imagen es de aspecto más heterogéneo y con menos certeza diagnóstica (81-83).

III.a.5. Endometriosis extra ovárica y extra peritoneal. Por otro lado, el diagnóstico de la endometriosis extra ovárica es de mucha mayor complejidad y con escaso aporte de la ultrasonografía convencional. En este tipo de endometriosis se incluye: endometriosis pelviana "profunda" (nódulos del fondo de saco de Douglas, afectación de los fórnices vaginales, compromiso de ligamentos útero-sacros, implantes murales recto-sigmoideos, focos del receso vésicouterino), endometriosis "cicatricial" (implantes en cicatriz de laparotomía, histerorrafia o episiotomía) y endometriosis "superficial" (implantes peritoneales pequeños). El enfrentamiento diagnóstico de estas lesiones peritoneales superficiales o profundas involucra el uso de RM (Figura 20B, C), que permite delimitar las lesiones relevantes con precisión y detectar la existencia de lesiones clínicamente no sospechadas (84-87). El diagnóstico de endometriosis profunda en RM se basa en la detección del proceso fibrótico reactivo que inducen los focos endometriales por sangrado recurrente. Esto lleva al desarrollo de masas nodulares y bandas fibróticas de baja señal en secuencias T2 en las localizaciones previamente descritas. En ocasiones, pequeños islotes de endometrio (hiperintensos en secuencias T2) o áreas de hemorragia recurrente (hiperintesos en secuencias T1) se detectan al interior de las alteraciones fibróticas. La RM también puede identificar nódulos hemorrágicos muy pequeñas en la superficie peritoneal pero su rendimiento para lesiones subcentimétricas se encuentra por debajo de la laparoscopia (Figura 14C) (88). Imágenes adicionales (Figura 20D) como el enema baritado, pielo-TAC o la endosonografía transrectal pueden contribuir ocasionalmente al estudio pre-operatorio de lesiones del tabique recto-vaginal, de gran volumen o con sospecha de compromiso rectal o ureteral $(89,90)$. La TC no juega un rol en el mapeo de la endometriosis pelviana pero ocasionalmente encuentra focos de compromiso intestinal o rectal en pacientes estudiados por síntomas de obstrucción intestinal o hemorragia digestiva (Figura 21). 


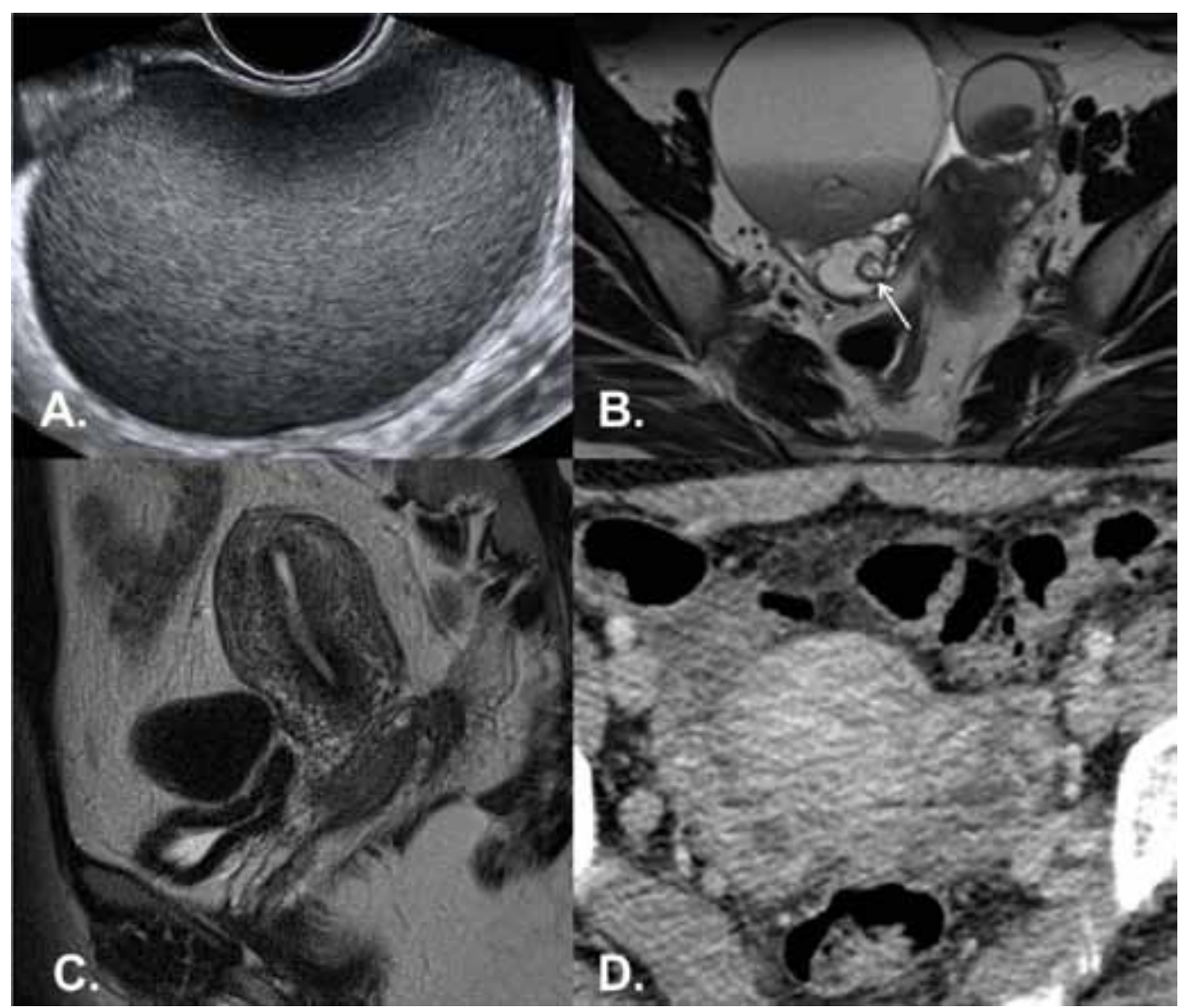

Figura 20. Endometriosis. Endometrioma ovárico en ecografía transvaginal (A) y resonancia magnética (B), este último es bilateral y en el ovario derecho coexiste con un teratoma ovárico (flecha). Implante endometriósico pélvico profundo en tabique rectovaginal por resonancia magnética (C) y tomografía computada (D).

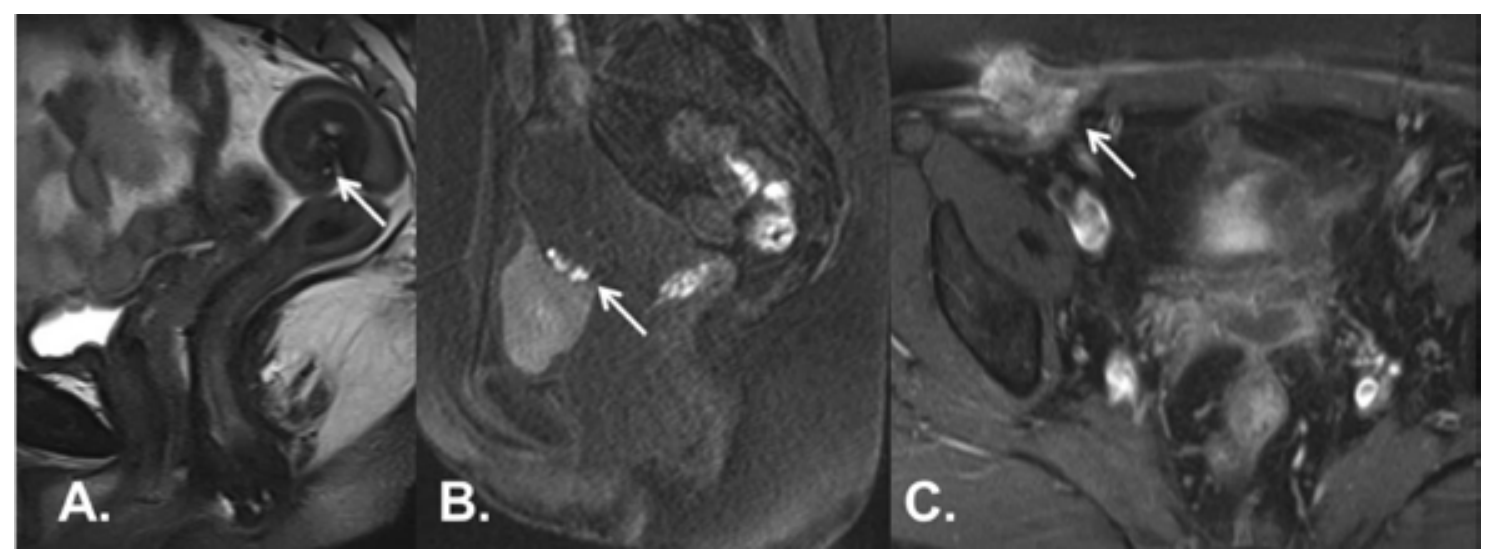

Figura 21. Endometriosis extragenital. Compromiso rectal por endometriosis con invasión mural (flechas) (A). Implantes endometriósicos hemorrágicos hiperintensos en T1 (flecha) en la pared vesical superior (B). Implante endometriósico en pared abdominal extendiéndose hacia el canal inguinal derecho (flecha) (C). 


\section{Estudio preoperatorio y control postoperatorio en ginecología}

En lesiones anexiales de gran tamaño, o ante la sospecha diagnóstica de una lesión neoplásica, es indispensable realizar exámenes complementarios, que permitan una mejor caracterización de la lesión y de su ubicación, para así lograr una adecuada planificación quirúrgica y etapificación. También, los métodos de imágenes avanzados ayudan al diagnóstico de complicaciones postoperatorias, tales como lesiones de la vía urinaria o asas intestinales (Figura 22) (91). En otros casos las condiciones de la paciente o la patología misma presenta limitaciones al manejo quirúrgico habitual (miomas de gran volumen, malformación vascular uterina, etc.), las que pueden ser tratadas por técnicas de imagenología intervencional, como la embolización selectiva de vasos pelvianos en el tratamiento no quirúrgico de miomas. Para este procedimiento, en primer lugar se caracteriza la irrigación arterial de la pelvis, mediante una angio-resonancia (Figura 23), para posteriormente cateterizar de manera selectiva estos vasos y así embolizar las ramas arteriales que se dirigen a miomas o malformaciones vasculares con el objetivo de reducir su tamaño (92).

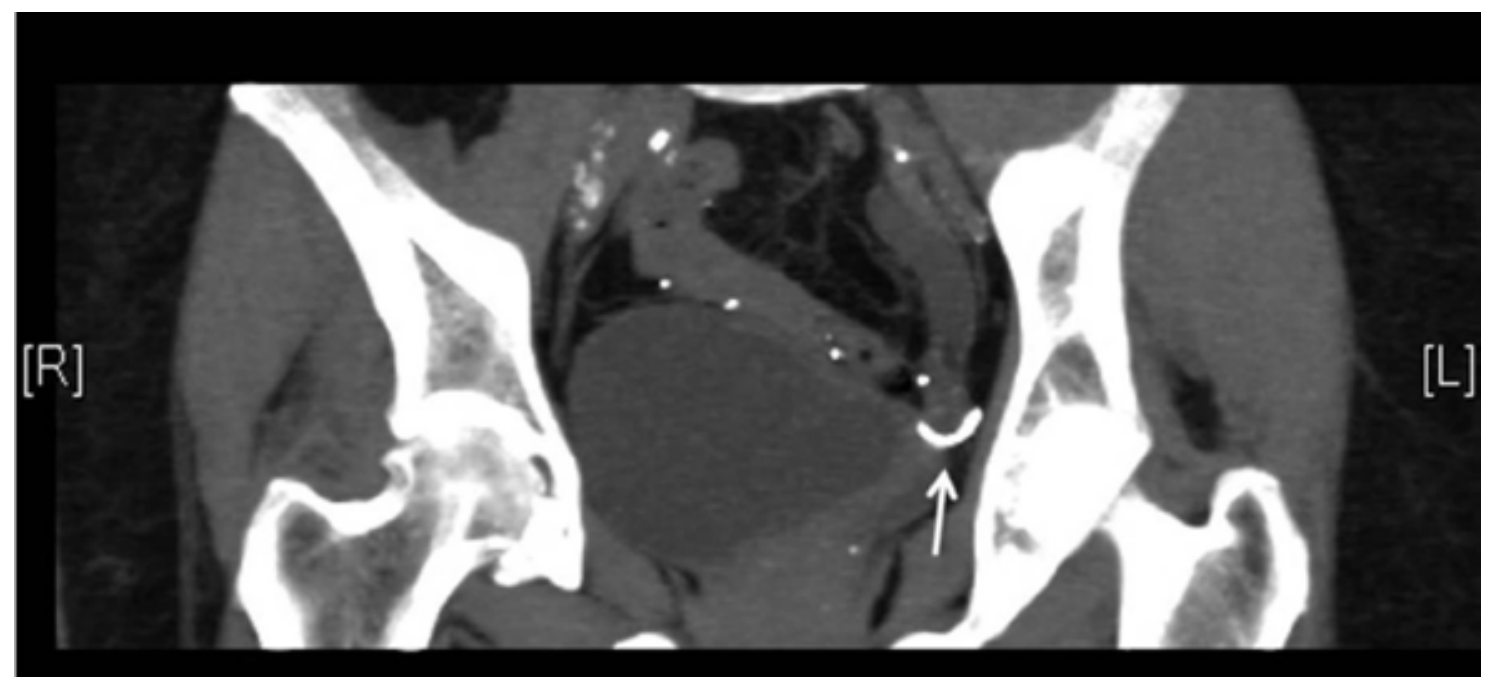

Figura 22. Otras imágenes en el manejo de patologías ginecológicas. Evaluación de complicación postoperatoria con TC donde se observa una hidroureteronefrosis izquierda secundaria a la presencia de una aguja de sutura retenida (flecha) en relación al trayecto distal del uréter post histerectomía total.

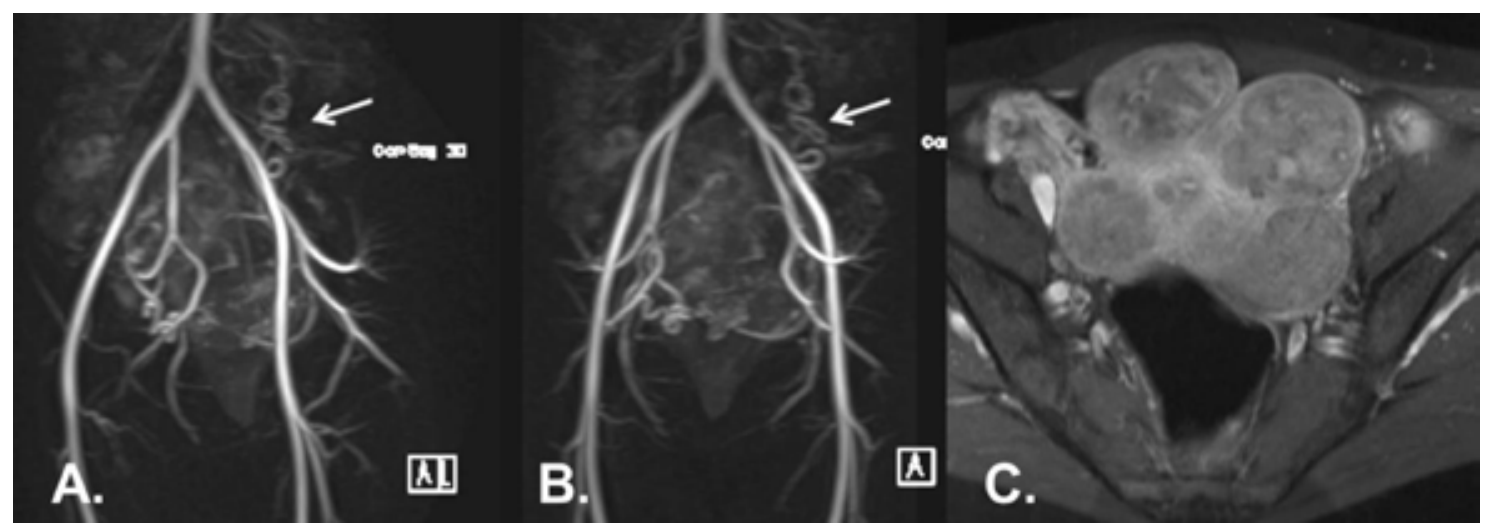

Figura 23. Angio-RM en el estudio pre-embolización de miomas uterinos. Proyección de máxima intensidad (MIP) coronal y oblicua $(A, B)$ demuestra hipertrofia de arterias uterinas mayor a derecha. Además releva hipertrofia de la arteria gonadal izquierda (flechas), vaso que también deberá ser embolizado para garantizar éxito del procedimiento. Corte axial contrastado en T1 (C) muestra múltiples miomas vascularizados que deforman los contornos uterinos. 


\section{CONCLUSIONES}

Tanto la ecografía como la TC y la RM, tienen ventajas y desventajas específicas. Las variables más importantes en el momento de elegir un método de apoyo diagnóstico son: su certeza diagnóstica, disponibilidad, costo y oportunidad de resultado. En éste contexto, la ecografía TV practicada por médicos debidamente adiestrados, es la técnica de primera línea para la adecuada caracterización de la mayoría de las patologías ginecológicas benignas y urgencias pelvianas.

LA TC y la RM no debieran ser utilizadas como exámenes de "segunda opinión" cuando un operador ecográfico no es capaz de caracterizar imágenes pelvianas. Lo mas costo-efectivo es pedir una segunda ecografía a un operador más experto, lo cual logra un diagnóstico correcto en más del $50 \%$ de éstos casos.

Las indicaciones de las técnicas avanzadas son limitadas y deber ser claramente conocidas por los clínicos:

1. Tomografía computada: En el diagnóstico diferencial de algunas urgencias ginecológicas y estudio preoperatorio en sospecha de compromiso de vías urinarias, ya sea pre-quirúrgico o por complicaciones post-operatorias (Uro-TAC). Evaluación y etapificación de lesiones anexiales complejas.

2. Resonancia magnética: Endometriosis profunda y extra pelviana, adenomiosis, malformaciones uterinas, miomas múltiples y extra pelvianos. Su rendimiento en la caracterización de tumores anexiales complejos no es superior a la de la TC.

Los gineco-obstetras deben conocer todos los métodos de imagen que se aplican en nuestra especialidad, tanto sus indicaciones, correlación clínicoimagenológica de sus resultados y saber cómo se complementan. Dado que la ecografía es la técnica de imagen ginecológica por excelencia, es indispensable que la realicen médicos adecuadamente formados y en constante actualización de sus conocimientos. En caso de requerir el apoyo de técnicas avanzadas, es fundamental que el equipo medico tratante aporte la información clínica relevante al momento del examen, para así facilitar una adecuada interpretación de los hallazgos. De la misma forma, la evaluación conjunta multidisciplinaria de casos complejos entre gineco-obstetras e imagenólogos dedicados contribuirá a lograr el mejor rendimiento de todas las técnicas en el estudio de las patologías descritas.

\section{REFERENCIAS}

1. Loy CT, Irwig L. Accuracy of diagnostic tests read with and without clinical information: a systematic review. JAMA 2004;292:1602-9.

2. Griscom NT. A suggestion: look at the images first, before you read the history. Radiology 2002;223:9-10.

3. Akobeng AK. Understanding diagnostic tests 2: likelihood ratios, pre- and post-test probabilities and their use in clinical practice. Acta Paediatr 2007;96:487-91.

4. Dubinsky TJ. Value of sonography in the diagnosis of abnormal vaginal bleeding. $\mathrm{J}$ Clin Ultrasound 2004;32:348-53.

5. Jeong YY, Outwater EK, Kang HK. Imaging evaluation of ovarian masses. Radiographics 2000;20:1445-70.

6. Tayal VS, Bullard M, Swanson DR, Schulz CJ, Bacalis $\mathrm{KN}$, Bliss SA, et al. ED endovaginal pelvic ultrasound in nonpregnant women with right lower quadrant pain. Am J Emerg Med 2008;26:81-5.

7. Valentin L. Imaging in gynecology. Best Pract Res Clin Obstet Gynaecol 2006;20:881-906.

8. Leslie A, Jones AJ, Goddard PR. The influence of clinical information on the reporting of $\mathrm{CT}$ by radiologists. Br J Radiol 2000;73:1052-5.

9. Bennet GL, Slywotzky CM, Giovanniello G. Gynecologic causes of acute pelvic pain: Spectrum of CT findings. Radiographics 2002;22:785-801.

10. Cicchiello LA, Hamper UM, Scoutt LM. Ultrasound evaluation of gynecologic causes of pelvic pain. Obstet Gynecol Clin North Am 2011;38:85-114, viii.

11. Vandermeer FQ, Wong-You-Cheong JJ. Imaging of acute pelvic pain. Clin Obstet Gynecol 2009;52:2-20.

12. Kamaya A, Shin L, Chen B, Desser TS. Emergency gynecologic imaging. Semin Ultrasound CT MR 2008;29:353-68.

13. Potter AW, Chandrasekhar CA. US and CT evaluation of acute pelvic pain of gynecologic origin in nonpregnant premenopausal patients. Radiographics 2008;28:1645-59.

14. MINSAL. Indicadores básicos de salud. Departamento de estadística en informática de salud; 2005.

15. Donoso $E$. ¿De qué mueren las madres chilenas en el siglo XXI?: cambio del perfil epidemiológico. Rev Chil Obstet Ginecol 2009;74:207-8.

16. Craig JM, Vaccaro $H$, Amor F, Araya A. Rol actual de la ultrasonografía en el diagnóstico del embarazo ectópico. Rev Chil Ultrasonog 2008;11:22-5.

17. Condous G, Okaro E, Khalid A, Lu C, Van Huffel S, Timmerman $\mathrm{D}$, et al. The accuracy of transvaginal ultrasonography for the diagnosis of ectopic pregnancy prior to surgery. Hum Reprod 2005;20:1404-9.

18. Casikar I, Reid S, Condous G. Ectopic pregnancy: Ultrasound diagnosis in modern management. Clin Obstet Gynecol 2012;55:402-9.

19. Condous G, Kirk E, Lu C, Van Huffel S, Gevaert O, De Moor B, et al. Diagnostic accuracy of varying discriminatory zones for the prediction of ectopic pregnancy in women with a pregnancy of unknown location. Ultrasound Obstet Gynecol 2005;26:770-5.

20. Bouquier J, Fauconnier A, Fraser W, Dumont A, Huchon C. [Diagnosis of pelvic inflammatory disease. Which clinical and paraclinical criteria? Role of imaging and laparoscopy?]. J Gynecol Obstet Biol Reprod (Paris) 2012;41:835-49.

21. Lin EP, Bhatt S, Dogra VS. Diagnostic clues to ectopic pregnancy. Radiographics 2008;28:1661-71.

22. Lao LY, Sheinfeld MH, Chernyak V, Rozenblit AM, Oh S. Dym RJ. Bejond ultrasound: CT and MRI of ectopic pregnancy. Am J Roentgenol 2014;202:904-11.

23. Chappell CA, Wiesenfeld HC. Pathogenesis, diagnosis, and management of severe pelvic inflammatory disease and tuboovarian abscess. Clin Obstet Gynecol 2012;55:893-903. 
24. Thomassin-Naggara I, Darai E, Bazot M. Gynecological pelvic infection: what is the role of imaging? Diagn Interv Imaging 2012;93:491-9.

25. Tukeva TA, Aronen HJ, Karjalainen PT, Molander $\mathrm{P}$, Paavonen T, Paavonen J. MR imaging in pelvic inflammatory disease: comparison with laparoscopy and US. Radiology 1999;210:209-16.

26. Potter AW, Chandrasekhar CA. US and CT evaluation of acute pelvic pain of gynecologic origin in nonpregnant premenopausal patients. Radiographics 2008;28:1645-59.

27. Amor F, Martínez J, Leyton M, Lira J, Vaccaro H, Gana SJ, et al. Cuerpo lúteo hemorrágico: oveja con piel de lobo. Rev Chil Obstet Ginecol 1998;68:276-81.

28. Shwayder JM. Pelvic pain, adnexal masses, and ultrasound. Semin Reprod Med 2008;26: 252-65.

29. Oelsner G, Cohen SB, Soriano D, Admon D, Mashiach $\mathrm{S}$, Carp $\mathrm{H}$. Minimal surgery for the twisted ischaemic adnexa can preserve ovarian function. Hum Reprod 2003;18:2599-602.

30. Shadinger LL, Andreotti RF, Kurian RL. Preoperative sonographic and clinical characteristics as predictors of ovarian torsion. J Ultrasound Med 2008;27:7-13.

31. Vijayaraghavan SB. Sonographic whirlpool sign in ovarian torsion. J Ultrasound Med 2004;23:1643-9; quiz 1650-1.

32. Auslender R, Shen O, Kaufman Y, Goldberg Y, Bardicef $\mathrm{M}$, Lissak $\mathrm{A}$, et al. Doppler and grayscale sonographic classification of adnexal torsion. Ultrasound Obstet Gynecol 2009;34:208-11.

33. Nizar K, Deutsch M, Filmer S, Weizman B, Beloosesky $\mathrm{R}$, Weiner Z. Doppler studies of the ovarian venous blood flow in the diagnosis of adnexal torsion. J Clin Ultrasound 2009;37:436-9.

34. Rha SE, Byun JY, Jung SE, Jung JI, Choi BG, Kim $B S$, et al. CT and MR imaging features of adnexal torsion. Radiographics 2002;22: 283-94.

35. Spalluto LB, Woodfield CA, DeBenedectis CM, Lazarus $E$. MR imaging evaluation of abdominal pain during pregnancy: appendicitis and other nonobstetric causes. Radiographics 2012;32:317-34.

36. Cullen IM, Cafferty F, Oon SF, Manecksha R, Shields $D$, Grainger R, et al. Evaluation of suspected renal colic with noncontrast CT in the emergency department: a single institution study. J Endourol 2008;22:2441-5.

37. Rao PM, Feltmate CM, Rhea JT, Schulick AH, Novelline RA. Helical computed tomography in differentiating appendicitis and acute gynecologic conditions. Obstet Gynecol 1999;93:417-21.

38. Pedrosa I, Levine D, Eyvazzadeh AD, Siewert B, Ngo L, Rofsky NM. MR imaging evaluation of acute appendicitis in pregnancy. Radiology 2006; 238:8919.

39. Mavrelos D, Naftalin J, Hoo W, Ben-Nagi J, Holland T, Jurkovic D. Preoperative assessment of submucous fibroids by three-dimensional saline contrast sonohysterography. Ultrasound Obstet Gynecol 2011;38:350-4.

40. Dueholm M, Lundorf E, Hansen ES, Ledertoug $S$, Olesen $F$. Evaluation of the uterine cavity with magnetic resonance imaging, transvaginal sonography, hysterosonographic examination, and diagnostic hysteroscopy. Fertil Steril 2001;76:350-7.

41. Kim HS, Baik JH, Pham LD, Jacobs MA. MRguided high-intensity focused ultrasound treatment for symptomatic uterine leiomyomata: long-term outcomes. Acad Radiol 2011;18:970-6.

42. Deshmukh SP, Gonsalves CF, Guglielmo FF, Mitchell DG. Role of MR imaging of uterine leiomyomas before and after embolization. Radiographics 2012;32:E25181.

43. Dueholm M, Lundorf E, Hansen ES, Ledertoug S, Olesen F. Accuracy of magnetic resonance imaging and transvaginal ultrasonography in the diagnosis, mapping, and measurement of uterine myomas. Am J Obstet Gynecol 2002;186:409-15.

44. Bazot M, Cortez A, Darai E, Rouger J, Chopier J, Antoine $\mathrm{JM}$, et al. Ultrasonography compared with magnetic resonance imaging for the diagnosis of adenomyosis: correlation with histopathology. Hum Reprod 2001;16:2427-33.

45. Novellas S, Chassang M, Delotte J, Toullalan O, Chevallier A, Bouaziz J, et al. MRI characteristics of the uterine junctional zone: from normal to the diagnosis of adenomyosis. AJR Am J Roentgenol 2011;196:1206-13.

46. Tamai K, Togashi $\mathrm{K}$, Ito $\mathrm{T}$, Morisawa N, Fujiwara $\mathrm{T}$, Koyama T. MR imaging findings of adenomyosis: correlation with histopathologic features and diagnostic pitfalls. Radiographics 2005;25:21-40.

47. Smith-Bindman $R$, Kerlikowske $K$, Feldstein VA, Subak L, Scheidler J, Segal M, et al. Endovaginal ultrasound to exclude endometrial cancer and other endometrial abnormalities. JAMA 1998;280:1510-7.

48. Dueholm M, Forman A, Jensen ML, Laursen $H$, Kracht P. Transvaginal sonography combined with saline contrast sonohysterography in evaluating the uterine cavity in premenopausal patients with abnormal uterine bleeding. Ultrasound Obstet Gynecol 2001;18:54-61.

49. Dueholm M, Jensen ML, Laursen $H$, Kracht $P$. Can the endometrial thickness as measured by trans-vaginal sonography be used to exclude polyps or hyperplasia in pre-menopausal patients with abnormal uterine bleeding? Acta Obstet Gynecol Scand 2001;80:64551.

50. Doubilet PM. Diagnosis of abnormal uterine bleeding with imaging. Menopause 2011:18:421-4.

51. Chang AS, Goldstein J, Moley KH, Odem RR, Dahan $\mathrm{MH}$. Radiologic and surgical demonstration of uterine polyposis. Fertil Steril 2005;84:1742-3.

52. Timmerman D, Verguts J, Konstantinovic ML, Moerman P, Van Schoubroeck D, Deprest J, et al. The pedicle artery sign based on sonography with color Doppler imaging can replace second-stage tests in women with abnormal vaginal bleeding. Ultrasound Obstet Gynecol 2003;22:166-71.

53. Fleischer AC. Color Doppler sonography of uterine disorders. Ultrasound Q 2003;19:179-89.

54. Fleischer AC, Shappell HW. Color Doppler sonohysterography of endometrial polyps and submucosal fibroids. J Ultrasound Med 2003;22:601-4.

55. Shi AA, Lee SI. Radiological reasoning: algorithmic workup of abnormal vaginal bleeding with endovaginal sonography and sonohysterography. AJR Am J Roentgenol 2008;191:S68-73.

56. Khan AT, Shehmar M, Gupta JK. Uterine fibroids: current perspective. Int J Womens Health 2014;6:95114.

57. Jurkovic D, Gruboeck K, Tailor A, Nicolaides KH. 
Ultrasound screening for congenital uterine anomalies. Br J Obstet Gynaecol 1997;104:1320-1.

58. Craig JM. Resultado reproductivo en mujeres con malformaciones uterinas. Utilidad de la ultrasonografía 2D y 3D. Rev Chil Ultrasonog 2007;10:108-13.

59. Behr SC, Courtier JL, Qayyum A. Imaging of mullerian duct anomalies. Radiographics 2012;32 E233-50.

60. Olpin JD, Heilbrun M. Imaging of Mullerian duct anomalies. Clin Obstet Gynecol 2009;52:40-56.

61. Deutch TD, Abuhamad AZ. The role of 3-dimensional ultrasonography and magnetic resonance imaging in the diagnosis of mullerian duct anomalies: a review of the literature. J Ultrasound Med 2008;27:413-23.

62. Salim R, Woelfer B, Backos M, Regan L, Jurkovic D. Reproducibility of three-dimensional ultrasound diagnosis of congenital uterine anomalies. Ultrasound Obstet Gynecol 2003;21:578-82.

63. Vallerie AM, Breech LL. Update in Mullerian anomalies: diagnosis, management, and outcomes. Curr Opin Obstet Gynecol 2010;22:381-7.

64. Kupesic S. Clinical implications of sonographic detection of uterine anomalies for reproductive outcome. Ultrasound Obstet Gynecol 2001;18:387400.

65. Santos XM, Krishnamurthy R, Bercaw-Pratt JL, Dietrich JE. The utility of ultrasound and magnetic resonance imaging versus surgery for the characterization of mullerian anomalies in the pediatric and adolescent population. J Pediatr Adolesc Gynecol 2012;25:181-4.

66. Cuello $M$, Merino $P$, Etchegaray $A$, Ortega JP, Pomés C, Barrena $\mathrm{N}$, et al. Distribución de la patología anexial en la mujer chilena: experiencia de la Universidad Católica de Chile. Rev Chil Obstet Ginecol 2004;69:429-40.

67. Kinkel K, Hricak H, Lu Y, Tsuda K, Filly RA. US characterization of ovarian masses: a meta-analysis. Radiology 2000;217:803-11.

68. Amor $\mathrm{F}$, Alcazar JL, Vaccaro $\mathrm{H}$, Leon $\mathrm{M}$, Iturra $\mathrm{A}$. GI-RADS reporting system for ultrasound evaluation of adnexal masses in clinical practice: a prospective multicenter study. Ultrasound Obstet Gynecol 2011;38:450-5.

69. Grab D, Flock F, Stohr I, Nussle K, Rieber A, Fenchel $\mathrm{S}$, et al. Classification of asymptomatic adnexal masses by ultrasound, magnetic resonance imaging, and positron emission tomography. Gynecol Oncol 2000;77:454-9.

70. Dodge JE, Covens AL, Lacchetti C, Elit LM, Le T, Devries-Aboud $\mathrm{M}$, et al. Preoperative identification of a suspicious adnexal mass: a systematic review and meta-analysis. Gynecol Oncol 2012;126:157-66.

71. Kalish GM, Patel MD, Gunn ML, Dubinsky TJ. Computed tomographic and magnetic resonance features of gynecologic abnormalities in women presenting with acute or chronic abdominal pain. Ultrasound Q 2007;23:167-75.

72. Hassanin-Negila A, Cardini S, Ladam-Marcus V, Palot JP, Diebold MD, Marcus C. [Endometriomas of the abdominal wall: Imaging findings]. J Radiol 2006;87:1691-5.

73. Gauche Cazalis C, Koskas M, Martin B, Palazzo L, Madelenat P, Yazbeck C. [Preoperative imaging of deeply infiltrating endometriosis in: Transvaginal sonography, rectal endoscopic sonography and magnetic resonance imaging]. Gynecol Obstet Fertil 2012;40:634-41.

74. Dodge JE, Covens AL, Lacchetti C, Elit LM, Le T, Devries-Aboud M, et al. Management of a suspicious adnexal mass: a clinical practice guideline. Curr Oncol 2012;19:e244-57.

75. Brun JL, Le Touze O, Leng JJ. [Medical and surgical treatment of functional ovarian cysts]. J Gynecol Obstet Biol Reprod (Paris) 2001;30:S41-52.

76. Rajkotia K, Veeramani M, Macura KJ. Magnetic resonance imaging of adnexal masses. Top Magn Reson Imaging 2006;17:379-97.

77. Rouanet JP, Maubon A, Juhan V, Meny R, Salanon AP, Daclin PY. [Imaging of benign ovarian tumors]. J Radiol 2000;81:1823-30.

78. Outwater EK, Siegelman ES, Hunt JL. Ovarian teratomas: tumor types and imaging characteristics. Radiographics 2001;21:475-90.

79. Damarey B, Farine M, Vinatier D, Collinet P, Lucot $\mathrm{J}$, Kerdraon $\mathrm{O}$, et al. [Mature and immature ovarian teratomas: US, CT and MR imaging features]. J Radiol 2010;91:27-36.

80. Saba L, Guerriero S, Sulcis R, Virgilio B, Melis G, Mallarini G. Mature and immature ovarian teratomas: CT, US and MR imaging characteristics. Eur J Radiol 2009;72:454-63.

81. Umaria N, Olliff JF. Imaging features of pelvic endometriosis. Br J Radiol 2001;74:556-62.

82. Choudhary S, Fasih N, Papadatos D, Surabhi VR. Unusual imaging appearances of endometriosis. AJR Am J Roentgenol 2009;192:1632-44.

83. Van Holsbeke C, Van Calster B, Guerriero S, Savelli L, Paladini D, Lissoni AA, et al. Endometriomas: their ultrasound characteristics. Ultrasound Obstet Gynecol 2010;35:730-40.

84. Kinkel K, Frei KA, Balleyguier C, Chapron C. Diagnosis of endometriosis with imaging: a review. Eur Radiol 2006;16:285-98.

85. Balleyguier C, Roupret M, Nguyen T, Kinkel K, Helenon O, Chapron C. Ureteral endometriosis: the role of magnetic resonance imaging. $\mathrm{J}$ Am Assoc Gynecol Laparosc 2004;11:530-6.

86. Balleyguier C, Chapron C, Chopin N, Helenon O, Menu $\mathrm{Y}$. Abdominal wall and surgical scar endometriosis: results of magnetic resonance imaging. Gynecol Obstet Invest 2003;55:220-4.

87. Haim N, Shapiro-Feinberg M, Zissin R. Incisional endometriomas: CT findings. Emerg Radiol 2005;11:162-3.

88. Abrao MS, Goncalves MO, Dias JA, Jr., Podgaec $\mathrm{S}$, Chamie LP, Blasbalg R. Comparison between clinical examination, transvaginal sonography and magnetic resonance imaging for the diagnosis of deep endometriosis. Hum Reprod 2007;22:3092-7.

89. Chamie LP, Blasbalg R, Pereira RM, Warmbrand $G$, Serafini PC. Findings of pelvic endometriosis at transvaginal US, MR imaging, and laparoscopy. Radiographics 2011;31:E77-100.

90. Bergamini V, Ghezzi F, Scarperi S, Raffaelli R, Cromi A, Franchi M. Preoperative assessment of intestinal endometriosis: A comparison of transvaginal sonography with water-contrast in the rectum, transrectal sonography, and barium enema. Abdom Imaging 2010;35:732-6. 
91. Aungst MJ, Sears CL, Fischer JR. Ureteral stents and retrograde studies: a primer for the gynecologist. Curr Opin Obstet Gynecol 2009;21:434-41.
92. Sanguin S, Lanta-Delmas S, Le Blanche A, GrardelChambenoit E, Merviel P, Gondry J, et al. [Uterine arteriovenous malformations: diagnosis and treatment in 2011]. Gynecol Obstet Fertil 2011;39:722-7. 